Hazel Pearson

Accepted to Natural Language and Linguistic Theory

\title{
The Semantics of Partial Control
}

Zentrum für Allgemeine Sprachwissenschaft (ZAS)

Schützenstrasse 18

10117 Berlin

Germany

Email: pearson.hazel@gmail.com

Phone: +49 (0)30 20192570

Fax: +49 30 20192-402

\begin{abstract}
In a partial control configuration the denotation of the controller is properly included in the understood subject of the infinitive. This paper proposes a compositional semantics for partial control - the first such proposal that we are aware of. We show that an account of what determines whether a given predicate licenses partial control follows naturally from the analysis without additional syntactic assumptions. At the heart of the proposal lies the idea that partial control predicates are attitude verbs and as such, quantify over a particularly finegrained type of modal base - so-called centred worlds. Unlike in traditional semantics for attitude reports, however, the lexical entry of these predicates requires that the property expressed by the control complement is applied not to the coordinates of this modal base, but rather to world, time and individual arguments that stand in a systematic relationship to those coordinates. This makes sense of the observation, going back to (Landau, 2000), that the ability of a control predicate to license partial control is intimately connected to its temporal properties.
\end{abstract}




\section{The Semantics of Partial Control}

\section{Introduction}

A partial control configuration is one where the individual denoted by the controller is a proper subset of the understood subject of the embedded clause. Here are some examples:

1a. John wanted to assemble in the hall.

1b. John expected to go on vacation together.

1c. John voted to work on the problem as a team.

1d. John promised to move the piano without damaging it.

Partial control (PC) presents a series of challenges for linguistic theory. The most general problem is to provide a syntax and semantics for partial control sentences that predicts that their understood subject is interpreted as a superset of the controller. Much attention has been devoted to this task by syntacticians (Barrie \& Pittman, 2004; Boeckx, Hornstein \& Nunes, 2010; Grano, 2012; Landau, 2000 et seq; Petter, 1998; Rodrigues, 2007; van Urk, 2010; Wilkinson, 1971; Witkos \& Snarska, 2008; Wurmbrand, 1998; Wurmbrand, 2001; Wurmbrand, 2002). On the other hand, there have been no attempts to date to provide an explicit semantics for partial control sentences. ${ }^{1}$ This paper is an attempt to fill this gap. We show that the proposed semantics makes correct predictions concerning the distribution and interpretation of partial control, thereby offering answers to the core questions raised by this phenomenon without additional syntactic or semantic assumptions.

For example, a theory of partial control should predict which control predicates license PC, and which do not. We have already seen that want, expect, vote and promise fall into the first class. Landau shows that try, manage, and dare are included in the latter category (2).

2a. *John tried to assemble in the hall.

2b. *John managed to go on vacation together.

2c. *John dared to work on the problem as a team.

3a. John and Mary tried to gather in the hall.

3b. John and Mary managed to go on vacation together.

3c. John and Mary dared to work on the problem as a team.

(3) exemplifies what Landau calls exhaustive control (EC); intuitively, the understood subject and controller are coreferential. (2) and (3) show that try, manage and dare license only exhaustive control; partial control is disallowed. Landau calls predicates of this class EC predicates. From our proposed semantics for PC will be derived a generalization and an explanation concerning what distinguishes the EC and the PC class. We take it that these classes consist of the following predicates ${ }^{2}$ :

\footnotetext{
1 (Jackendoff and Culicover, 2003) advocate a semantic approach to partial control. Problems with their approach are discussed in (Landau, 2013a). See also (Hornstein, 2003), who suggests that partial control may not involve a distinct syntax from exhaustive control, but instead arises via a meaning postulate associated with the semantics of the PC class. With neither of these approaches was a complete compositional semantics for PC provided.

2 These lists are based on the useful characterization of the PC and EC classes in (Landau, 2000). The most important differences between his lists and ours are (i) our re-classification of claim and pretend as members of the EC class, based on data that will be introduced in section 3.4; (ii) the addition to the PC class of the verbs expect, vote, advise, recommend and a variant of remember that takes a gerundive complement, which we call remembersc; (iii) the addition to the EC class of the
} 


\section{Partial control predicates}

glad, sad, regret, remember ${ }_{\mathrm{PC}}$, like, dislike, hate, loath, surprised, shocked, sorry, enjoy, imagine, deny, want, prefer, yearn, arrange, hope, afraid, refuse, agree, plan, aspire, decide, mean, intend, resolve, strive, demand, promise, choose, offer, eager, ready, wonder, ask, find out, interrogate, inquire, contemplate, deliberate, guess, grasp, understand, know, unclear, expect, vote, advise, recommend.

\section{Exhaustive control predicates}

try, dare, manage, make sure, bother, rememberEc, get, see fit, condescend, avoid, forget, refrain, decline, neglect, force, compel, fail, begin, start, continue, finish, stop, resume, have, need, may, should, is able, must, deserve, claim, pretend.

Next, a theory of partial control must account for the fact that in PC, the understood subject behaves in some ways like a plural and in others like a singular expression. (1a-c) provide motivation for the thought that PRO is plural-like: it can combine with a predicate that can otherwise only take plural subjects. On the other hand, (Landau, 2000) shows convincingly that the understood subject fails to license a host of configurations associated with plural subjects: reciprocals (6a), plural reflexives (6b), predicates including plural morphology (6c) and floated quantifiers (6d).

6a. *John wanted to meet each other in the hall.

6b. *John expected to pamper themselves on vacation.

6c. *John voted to become members of the new club.

6d. *John promised to all be careful when they moved the piano.

Broadening our focus slightly, we would also like to know why the subset-superset relation between antecedent and infinitival subject is confined to control - why is there no partial raising?

7a. *John seemed to assemble in the hall.

7b. *John is likely to go on vacation together.

7c. *John appeared to work on the problem as a team.

We argue that these questions can be answered by treating PC predicates as modal quantifiers of a particularly fine-grained sort: the elements quantified over are 'centred worlds' - triples consisting of a world, time and individual as argued in a significant body of literature on attitude reports (Abusch, 1997a; Anand, 2006; Chierchia, 1990; Lewis, 1979; Percus \& Sauerland, 2003; Stephenson, 2007; Stephenson, 2010). According to one influential view, control infinitives express properties, which take the coordinates of these triples as their individual, time and individual arguments (Chierchia, 1990). We propose that in PC, the arguments of the property are not directly supplied by the modal base associated with the predicate, but are instead individuals, times and worlds that stand in a systematic relationship to the coordinates of the modal base: an inclusion relation for individuals, and either inclusion or temporal precedence for times. This derives the partial control interpretation and makes correct predictions for the temporal properties of predicates in the PC class. The implementation of the idea involves amending the semantics of PC predicates to incorporate

verb deserve. (Bowers, 2008) disputes the notion that control predicates can be divided into a class that permit PC and a class that do not, and indeed intuitions regarding partial control are notoriously delicate, so that this is an area that is ripe for experimental research. See (White \& Grano, 2013) for a recent experimental study of grammaticality judgments about partial control that lends overall support to the characterization of the empirical landscape given in this paper. 
existential quantification over 'extensions' - tuples of a world, time and individual that stand in a systematic relation to the elements of the modal base. This predicts that predicates that license PC also license particular types of temporal shift - an observation that has been known about since (Landau, 2000) and now receives a principled explanation. Beyond the analysis of PC, the paper contributes to (i) our understanding of the semantics of attitude predicates and how they differ from ordinary modals, particularly in the realm of so-called 'de se' attitudes and (ii) our understanding of the role of semantics in the encoding of temporal notions in infinitives.

The paper is structured as follows. Section 2 lays out background on the semantics of control, with close attention to the question of how to account for the obligatorily 'de se' interpretation of PRO, and Chierchia's response that control infinitives express properties. It then considers how this view can be reconciled with the existence of partial control, giving two candidate semantics for PC that both maintain the property view. Candidate I treats partial control predicates as quantifiers over world-time-individual triples, with the individual coordinate being shifted in order to derive PC. Candidate II shifts all three coordinates of the modal base wholesale. Section 3 shows that candidate II makes correct predictions regarding membership of the PC class: all partial control predicates are attitude predicates, and all partial control predicates permit the embedded event to be interpreted as non-simultaneous with the event described by the control predicate itself. Section 4 shows that the analysis provides the basis for answers to the core questions concerning PC, while section 5 considers further issues and directions for future work. Section 6 concludes.

\section{Background on the semantics of control}

\subsection{The de se interpretation of PRO}

Many control verbs are attitude predicates - verbs of mental attitude or communication like want, expect and claim. Control with an attitude predicate is the paradigm case of a linguistic configuration that obligatorily expresses a so-called 'attitude de se' (Chierchia, 1990; Morgan, 1970). Intuitively, an attitude de se is an attitude whose content the bearer of the attitude (henceforth the 'attitude holder') would be disposed to express using the first person pronoun. We assume the following definition:

8. An attitude de se is an attitude - a belief, desire, expectation etc. - that has the following properties:

(i) the attitude is about the attitude holder and (aboutness condition)

(ii) the attitude holder is aware that the attitude is about herself (awareness condition)

If John wants, expects, or claims to be a great linguist, then his desire, expectation or claim concerns himself. So attitudes reported by control sentences satisfy the aboutness condition. To show that they satisfy the awareness condition, we must establish that they are judged false in situations where the attitude holder is unaware that the attitude is about herself. Compare for example (9a) and (9b).

9. Context: John is an amnesiac. He reads a linguistics article that he bimself wrote, although he has forgotten this fact. Impressed, he remarks, 'The author of this paper will become rich and famous. Unfortunately, I won't.'. a. John expects [PRO to become rich and famous].

b. John expect [that he will become rich and famous].

(9a) is false in the context described, but there is a reading of (9b) upon which it is true (Chierchia, 1990; Morgan, 1970). Control sentences are therefore subject to the awareness condition: that John is unaware that his remark is about himself in (9) renders the control sentence false in this scenario. 
Thus a semantics of control should capture the fact that when obligatorily controlled PRO is introduced by an attitude predicate, it must be construed de se.

There are two major families of proposals regarding the proper semantic treatment of control infinitives and gerunds: those that analyze them as expressing properties (Bach, 1979; Chierchia, 1984; Chierchia, 1989; Chierchia, 1990; Clark, 1990; Dowty, 1985; Lebeaux, 1985; Williams, 1980), and those that treat them as expressing propositions (much work in syntactic theory seems to take this as a given; (Landau, 2000) explicitly argues for this view).

In (10) we provide an LF for (9a) that is commensurate with the view that control infinitives are interpreted as properties. It is based on (Chierchia, 1990).

10. [ ${ }_{\mathrm{CP} 1} \lambda \mathrm{w}_{1}\left[\mathrm{w}_{1}\right.$ John expects $\left[{ }_{\mathrm{CP} 2} \lambda \mathrm{x}_{2} \lambda \mathrm{w}_{3}\left[{ }_{\mathrm{IP}} \mathrm{w}_{3} \mathrm{PRO}_{2}\right.\right.$ to become rich and famous]]]]

The left periphery of the embedded clause is occupied by abstractors over worlds and individuals that bind co-indexed elements of the appropriate type in their scope. According to this view, PRO is obligatorily bound, and the infinitive winds up expressing a property of individuals, type $<\mathrm{e},<\mathrm{s}, \mathrm{t}>>$.

(Lewis, 1979) proposed that an attitude de se involves self-ascription of some property on the part of the attitude holder - the property of becoming rich and famous, say. If so, then (10) is a promising way to represent the structure that is passed to the semantic component.

To verify this, we need a semantics for the control predicate whereby it takes an argument of the appropriate type, $<\mathrm{e},<\mathrm{s}, \mathrm{t}>>$, in addition to the individual argument (the attitude holder). Verbs of speech or mental attitude are traditionally treated as modal quantifiers (Hintikka, 1969). Beliefs, for instance, concern which of all possible worlds might be the actual world. ${ }^{3}$ Given that none of us is omniscient, no attitude holder is in a position to identify a single world as the actual world, but her mental state instead distinguishes a set of candidates for the actual world. In order for a world w' to be a member of this set of candidates, the attitude holder's belief state must not rule out the possibility that w' is the actual world. That is to say, it must be compatible with what the attitude holder believes for w' to be the actual world. Call this set the attitude holder's doxastic alternatives:

\section{Doxastic alternatives: version 1 (Hintikeka-style)}

$\operatorname{Dox}_{\mathrm{x}, \mathrm{w}}=\left\{\mathrm{w}^{\prime}:\right.$ it is compatible with what $\mathrm{x}$ believes in $\mathrm{w}$ for $\mathrm{w}$ to be $\left.\mathrm{w}^{\prime}\right\}$

The verb believe universally quantifies over the worlds in this set. Intuitively, if John believes that it is raining, then it is raining in each of John's candidates for the actual world. Thus John believes that it is raining reports that for each of those worlds w' such that John's beliefs do not rule out the possibility that $\mathrm{w}$ ' is the actual world, it is raining. The lexical entry for believe can then be stated as follows:

\section{Lexical entry of believe: version 1 (Hintikeka-style)}

【believe $\rrbracket^{c, g}=\lambda \mathrm{p}_{<\mathrm{s}, \mathrm{t}} \lambda \mathrm{x}_{\mathrm{e}} \lambda \mathrm{w}_{\mathrm{s}} . \forall \mathrm{w}^{\prime}\left[\mathrm{w}^{\prime} \in \operatorname{Dox}_{\mathrm{x}, \mathrm{w}} \longrightarrow \mathrm{p}\left(\mathrm{w}^{\prime}\right)\right]$

A glance at the types reveals that some adjustment must be made to reconcile the idea that control infinitives express properties with the treatment of attitude predicates as modal quantifiers: according to (12), believe takes as its first argument a function which when applied to an element of the set of doxastic alternatives (a world) returns a truth value. Such a function is of type $<\mathrm{s}, \mathrm{t}>$, not

\footnotetext{
${ }^{3}$ We focus on believe for expository purposes, even though it is not a control predicate in English. It is in many other languages though, including Italian, French and German. Furthermore, the discussion will provide us with the tools to analyze expect, since expectations are merely beliefs about what will happen in the future, as (Lewis, 1979) noticed.
} 
type $<\mathrm{e},<\mathrm{s}, \mathrm{t}>>$; it is a proposition, not a property. Since properties are functions from worldindividual pairs to truth values, doxastic alternatives must be world-individual pairs, not worlds:

\section{Doxastic alternatives: version 2 (Lewis/Chierchia-style)}

$\operatorname{Dox}_{\mathrm{x}, \mathrm{w}}=\left\{<\mathrm{w}, \mathrm{y}>\right.$ : it is compatible with what $\mathrm{x}$ believes in $\mathrm{w}$ for $\mathrm{x}$ to be $\mathrm{y}$ in $\left.\mathrm{w}^{\prime}\right\}$

According to this view, a belief is not a representation merely of the worlds that the attitude holder considers might be the actual world, but rather of the pairs of worlds and individuals that the attitude holder takes to be candidates for herself and the actual world. Such pairs are called 'centred worlds': they pair a world w' with a distinguished individual in w', the so-called 'doxastic centre'.

At this point one is tempted to ask why an attitude holder would have candidates for herself. After all, we are typically well informed about the facts that make us identifiable. I know what my name is, my biographical information, where I am right now, and (unlike John), which papers I have written. But in the mistaken identity scenarios used to discern de se interpretations, there is some relevant fact about the attitude holder that she herself is unaware of, as when John fails to realize that he is the author of the paper that he is reading. Consequently for any $<w$ ', $y>$ that is a member of John's doxastic alternatives, $y$ is not the author of the paper in w'. Since it is the author of the paper that John believes will become rich and famous, and he believes that he himself will not, it follows that for any $<w$, $y>$ included in John's doxastic alternatives, $y$ will not become rich and famous in w'.

This suggests that the treatment of doxastic alternatives as world-individual pairs rather than merely worlds has the potential to provide a way of modeling attitudes de se. By employing this notion, we can now give a lexical entry for believe that is commensurate with the property view:

\section{Lexical entry of believe: version 2 (Lewis/Chierchia-style)}

$\llbracket$ believe $\rrbracket^{c, g}=\lambda \mathrm{P}_{<\mathrm{e},<\mathrm{s}, \mathrm{t}>>} \lambda \mathrm{x}_{\mathrm{e}} \lambda \mathrm{w}_{\mathrm{s}} . \forall<\mathrm{w}^{\prime}, \mathrm{y}>\left[<\mathrm{w}^{\prime}, \mathrm{y}>\in \operatorname{Dox}_{\mathrm{x}, \mathrm{w}} \longrightarrow \mathrm{P}(\mathrm{y})\left(\mathrm{w}^{\prime}\right)\right]$

Now let us apply this thinking to our original control example. Since believe is not a control predicate in English, we used expect as the embedding verb.

\section{John expects to become rich and famous.}

Reports of what an attitude holder expects to happen describe beliefs of a particular kind. As noted in (Lewis, 1979), the expectation kind of belief is oriented towards the future: (15) means roughly that John believes that he will become rich and famous. We therefore need a way to model the temporal dimension of control sentences that report attitudes. In fact, we will end up claiming that PC is derived by the same machinery that derives temporal shifts such as we find with expect.

For now, however, let us simply say that expect is a universal quantifier over a particular kind of doxastic alternative that concerns the attitude holder's candidates for future rather than present realities. We will call this special kind of doxastic alternative an expect-alternative. Don't worry for now about the details of how to define expect-alternatives. For the moment we will simply say that they are that kind of doxastic alternative that has a future-orientation. Like doxastic alternatives, they designate an individual y in a world w' as the attitude holder's candidate for herself in w'. Precisely how the future-orientation is encoded formally is an issue we will return to in a moment. Here then is a preliminary lexical entry for expect and semantics for a control sentence involving this verb. 
16. Lexical entry of expect: version 1

$\llbracket$ expect $\rrbracket^{c, g}=\lambda \mathrm{P}_{<\mathrm{e},<\mathrm{s}, \mathrm{t}>>} \lambda \mathrm{x}_{\mathrm{e}} \lambda \mathrm{w}_{\mathrm{s}} . \forall<\mathrm{w}^{\prime}, \mathrm{y}>\left[<\mathrm{w}^{\prime}, \mathrm{y}>\in \operatorname{Expect}_{\mathrm{x}, \mathrm{w}} \rightarrow \mathrm{P}(\mathrm{y})\left(\mathrm{w}^{\prime}\right)\right]$

17a. [ ${ }_{\mathrm{CP} 1} \lambda \mathrm{w}_{1}\left[\mathrm{w}_{1}\right.$ John expects $\left[\mathrm{CP}_{2} \lambda \mathrm{x}_{2} \lambda \mathrm{w}_{3}\left[\mathrm{IP}_{3} \mathrm{w}_{3} \mathrm{PRO}_{2}\right.\right.$ to become rich and famous]]]]

17b. [CP2 $\rrbracket^{c, g}=\lambda x \lambda w . x$ is rich and famous in $w$

17c. $\llbracket C P 1 \rrbracket^{c, g}=\lambda$ w. $\forall<w^{\prime}, y>\left[<w^{\prime}, y>\in\right.$ Expect $_{\text {John,w }} \rightarrow$ y becomes rich and famous in w']

This lets us understand why (9a) is false in the context described. John believed of the author of the paper that he would be rich and famous, unaware that he was referring to himself. Therefore, there are members of the set of world-individual pairs $<w, y>$ quantified over by expect such that $y$ is not rich and famous in w' - that is, where application of the property expressed by the embedded clause to $\mathrm{x}$ and $\mathrm{w}$ yields falsehood. This is sufficient to falsify the sentence.

The centred worlds based semantics for control sentences involving attitude verbs makes it possible to solve a variety of puzzles concerning the interpretation of PRO. Let us employ an example from French, where believe is a control predicate. Suppose that Mary is deluded, and believes that she is Napoleon. A French speaker could report that state of affairs as follows:

18. Marie crois être Napoleon

Mary believe COP Napoleon

'Mary believes that she is Napoleon' (Literally: 'Mary believes to be Napoleon.')

In cases of EC such as this, we are accustomed to thinking of PRO as being coreferential with its controller. But then (18) should report that Mary believes that Mary is Napoleon. That cannot be: there is no world in which Mary is Napoleon. The property view easily accommodates examples of this sort. According to this view, PRO is not referential at all, but is rather a lambda abstracted variable. What (18) reports is Mary's self-ascription of the property of being Napoleon, or more precisely that for each of Mary's doxastic alternatives $\langle w, y\rangle$, the property of being Napoleon is true of $y$ in w'. Such a situation will obtain whenever any y such that $y$ is a candidate of Mary's for herself is Napoleon - that is, in precisely the scenario that we are entertaining. ${ }^{4}$

We have seen that the property view satisfies an important desideratum for any semantics of control: it correctly predicts that when PRO is introduced by an attitude predicate, it is obligatorily interpreted de se. However, (Landau, 2000) argues that the existence of partial control is a serious, perhaps even fatal problem for any theory that treats a control complement as expressing a property rather than a proposition. This paper defends the property view against this charge. We will show that Chierchia's analysis of control can be built upon to give a semantics of partial control that (i) correctly predicts whether a given predicate belongs to the PC or EC class, (ii) explains why partially controlled PRO behaves in some ways as though it is singular and in other ways as though it is plural, and (iii) answers the question of why there is no partial raising.

\footnotetext{
${ }^{4}$ Notice that this argumentation suggests that when believe embeds an overt de se pronoun, as in Mary $_{i}$ believes that she ${ }_{i}$ is Napoleon, the embedded clause should also be of property type. Chierchia accommodates this by letting attitude verbs that take finite complements be ambiguous between a Hintikka- and a Lewis/Chierchia-style semantics. If the pronoun is interpreted de se, as in the Napoleon case, it is abstracted over at LF, and the latter type of semantics is assigned to the attitude verb. An alternative is to treat de se pronouns in finite clauses as de re expressions, interpreted with respect to the acquaintance relation of identity (Reinhart, 1990; Schlenker, 2003; Anand, 2006; Maier, 2009, 2011). We have nothing to add to the discussion of attitude reports with finite complements in this paper.
} 


\subsection{Reconciling partial control with the property view}

Why should PC be a threat to the property view? Suppose that the theory described in the last subsection is correct: the control infinitive expresses a property that is self-ascribed by the individual denoted by the controller - or more precisely, is applied to the controller's 'doxastic centre', the candidates for herself distinguished by the individual coordinates of the centred worlds quantified over by the control predicate. Presumably, any individual that an (atomic) attitude holder considers a candidate for herself must also be an atomic individual. If I wake up tomorrow with amnesia I might find myself in a situation where I am unsure whether I am Mary, Jane or Bill, but I will be certain that I am at most one of them. Consequently, if a controller DP denotes an atomic individual John, say - and the infinitive contains a collective predicate such as assemble in the hall, then the resulting sentence should be semantically anomalous: the property expressed by the infinitive should not be applicable to an atomic individual such as John or John's candidates for himself.

But is this really a fatal problem for the property view? Take the sentence John expected to assemble in the ball. Suppose that the infinitive does indeed express the property of assembling in the hall:

19a. $\left[\lambda \mathrm{x}_{1} \lambda \mathrm{w}_{2}\left[\mathrm{w}_{2} \mathrm{PRO}_{1}\right.\right.$ to assemble in the hall $\left.]\right]$

19b. $\llbracket 19 \mathrm{a} \rrbracket^{c, g}=\lambda x \lambda w . x$ assembles in the hall in $\mathrm{w}$

Intuitively, this property should be applied to a plural individual that includes but is not limited to John. If John expected to assemble in the hall, then he expected that some group including him would assemble in the hall. In the centred worlds framework, this means that at each of John's expect-alternatives $\langle\mathrm{w}, \mathrm{y}\rangle$, there is a $\mathrm{z}$ that includes $\mathrm{y}$ such that the property of assembling in the hall is true of $z$ in w'. So the truth conditions of the PC sentence might look like this:

\section{Semantics of partial control: candidate I}

$\mathbb{[}\left[{ }_{\mathrm{CP} 1} \lambda \mathrm{w}_{1}\left[\mathrm{w}_{1}\right.\right.$ John expects $\left[{ }_{\mathrm{CP} 2} \lambda \mathrm{x}_{2} \lambda \mathrm{w}_{3}\left[_{\mathrm{IP}_{\mathrm{P}}} \mathrm{w}_{3} \mathrm{PRO}_{2}\right.\right.$ to assemble in the hall]]]] $\rrbracket=\lambda \mathrm{w} . \forall<\mathrm{w}^{\prime}, \mathrm{y}>\left[<\mathrm{w}^{\prime}\right.$, $\mathrm{y}>\in$ Expect $_{\text {John,w }} \longrightarrow \exists_{\mathrm{z}}\left[\mathrm{y} \leq \mathrm{z} \& \mathrm{z}\right.$ assembles in the hall in $\left.\left.\mathrm{w}^{\prime}\right]\right]$

Where $\mathrm{a} \leq \mathrm{b}$ iff $\mathrm{a}$ is part of $\mathrm{b}$.

Contrary to Landau's claim, then, it is possible to provide a semantics of PC that is compatible with the view that control complements are of property type. This is not yet a complete theory. For instance, we do not yet have an answer to why some control predicates permit partial control and others do not. Furthermore, we still have not explained how the future-orientation of expect is derived. We shall address this issue first, and then show how it sheds light on the others.

In order to model the future-orientation of expect, we need a way to encode temporal notions in attitude reports. This will require an adjustment to our semantics for attitudinal control predicates, and to the corresponding LFs. As argued in (Abusch, 1997a), an attitude holder's mental state not only distinguishes her candidates for herself, but also distinguishes her candidates for the actual time - what is known as the attitude holder's subjective 'now'. This is because just as we can be mistaken about who we are, as when Mary believes that she is Napoleon, we can also be mistaken about what time it is, as when (21) is uttered at 4pm.

21. Bill believes that it is $3 \mathrm{pm}$. 
Suppose that Bill does not know that the clocks have gone forward, and consequently locates himself at a time other than the actual time. Suppose also that the present tense denotes that actual time. Then (21) reports that John believes that $4 \mathrm{pm}$ is $3 \mathrm{pm}$. This is the same problem as we ran into in the case of Mary believing that she is Napoleon, only in the domain of tense: there is no world where $4 \mathrm{pm}$ is $3 \mathrm{pm}$. The remedy in the former case was to let believe be a quantifier over worldindividual pairs $<\mathrm{w}, \mathrm{y}>$, and have the subject be bound by an individual abstractor, rather than being referential. We can apply the same solution to the temporal domain. That is, we can let attitude predicates such as believe be quantifiers over world-time-individual triples $<\mathrm{w}^{\prime}, \mathrm{t}^{\prime}, \mathrm{y}>$ :

\section{Lexical entry of believe: final version}

【believe】 $\rrbracket^{c, g}=\lambda \mathrm{P}_{<\mathrm{e},<\mathrm{i},<\mathrm{s}, \mathrm{t}>>>} \lambda \mathrm{x}_{\mathrm{e}} \lambda \mathrm{t}_{\mathrm{i}} \lambda \mathrm{w}_{\mathrm{s}} . \forall<\mathrm{w}^{\prime}, \mathrm{t}^{\prime}, \mathrm{y}>\left[<\mathrm{w}^{\prime}, \mathrm{t}^{\prime}, \mathrm{y}>\in \operatorname{Dox}_{\mathrm{x}, \mathrm{tw}} \rightarrow \mathrm{P}(\mathrm{y})\left(\mathrm{t}^{\prime}\right)\left(\mathrm{w}^{\prime}\right)\right]$

Where $\operatorname{Dox}_{\mathrm{x}, \mathrm{w}, \mathrm{t}}=\left\{\left\langle\mathrm{w}^{\prime}, \mathrm{t}^{\prime}, \mathrm{y}\right\rangle\right.$ : it is compatible with what $\mathrm{x}$ believes in $\mathrm{w}$ at $\mathrm{t}$ for $\mathrm{x}$ to be $\mathrm{y}$ in $w^{\prime}$ and for $\mathrm{t}$ to be t'\}

We adopt from (Bennett \& Partee, 1972) the idea that temporal notions are encoded in terms of time intervals - sets of moments in time, type i. Properties take time interval arguments as well as individual and world arguments; they are of type $<\mathrm{e},<\mathrm{i},<\mathrm{s}, \mathrm{t}>>>$. Since believe is a quantifier over world-time-individual triples it introduces abstractors over individuals, time intervals and worlds in the left periphery of the embedded clause. By analogy with the account of the de se construal of PRO, embedded present tense in (21) should be semantically vacuous and bound by the embedded temporal abstractor. This is obtained by assuming that semantic binding of tense results in deletion of the value of this operator, so that [pres] is invisible to the semantic interpretation (Ogihara, 1996; von Stechow, 2002; von Stechow, 2003). The interpretation of (21) can be paraphrased as 'for all times $t^{\prime}$ such that it is compatible with what Bill believes in $\mathrm{w}$ at $\mathrm{t}$ for $\mathrm{t}$ to be $\mathrm{t}^{\prime}, \mathrm{t}^{\prime}=3 \mathrm{pm}$ '. Since $\mathrm{t}^{\prime}$ need not be the actual time, no contradiction arises.

We have described an argument that in attitude reports, the subjective 'now' is encoded via a temporal coordinate for the objects quantified over by the attitude verb. We follow (Abusch, 2004) in assuming that with future-oriented predicates such as expect, the temporal coordinate of these alternatives also corresponds to the subjective 'now', rather than some future time. This reflects the intuition that when we learn that John expects to become rich and famous, we learn that he has the thought, "I will become rich and famous". The predicted event is located at a time in the future with respect to John's subjective 'now', which may or may not be the actual time. Whatever centred worlds $<\mathrm{w}$ ', t', $\mathrm{y}>$ are quantified over by expect, then, t' must simply be the subjective 'now'. This entails that the temporal argument of a predicate embedded below expect cannot be t', but some t" that is in the future with respect to t'. The source of the future-orientation of expect cannot lie in the expect-alternatives themselves. In fact, since expectation is simply future-oriented belief, the elements quantified over by expect are nothing other than doxastic alternatives.

How, then, is the future-orientation derived? One option is to posit some sort of covert temporal operator in the infinitive, which shifts the temporal argument of the embedded predicate forward with respect to the attitude holder's subjective 'now' (Abusch, 2004). In this paper, we explore a different option, namely that the future-orientation is built into the semantics of the embedding verb itself. The lexical entry of expect might then look like this:

23. Lexical entry of expect: version 2

$\llbracket$ expect $\rrbracket^{\mathrm{c}, \mathrm{g}}=\lambda \mathrm{P}_{<\mathrm{e},<\mathrm{i},<\mathrm{s}, \mathrm{t}>>>} \lambda \mathrm{x}_{\mathrm{e}} \lambda \mathrm{t}_{\mathrm{i}} \lambda \mathrm{w}_{\mathrm{s}} . \forall<\mathrm{w}^{\prime}, \mathrm{t}^{\prime}, \mathrm{y}>\left[<\mathrm{w}^{\prime}, \mathrm{t}, \mathrm{y}>\in \operatorname{Dox}_{\mathrm{x}, \mathrm{w}, \mathrm{t}} \longrightarrow \exists \mathrm{t}^{\prime \prime}\left[\mathrm{t}^{\prime}<_{\text {precedes }} \mathrm{t}^{\prime \prime} \&\right.\right.$ $\left.\left.\mathrm{P}(\mathrm{y})\left(\mathbf{t}^{\prime}\right)\left(\mathrm{w}^{\prime}\right)\right]\right]$ 
This lexical entry delivers the following interpretation for John expects to become rich and famous:

24. [ [ [CP1 $\lambda \mathrm{t}_{1} \lambda \mathrm{w}_{2}\left[\mathrm{w}_{2} \mathrm{t}_{1}\right.$ John expects [ ${ }_{\mathrm{CP} 2} \lambda \mathrm{x}_{3} \lambda \mathrm{t}_{4} \lambda \mathrm{w}_{5}\left[\mathrm{w}_{5} \mathrm{t}_{4} \mathrm{PRO}_{3} \text { to become rich and famous]]]] }\right]^{\mathrm{c}, g}=$ $\lambda+\lambda$ w. $\forall<\mathrm{w}^{\prime}, \mathrm{t}^{\prime}, \mathrm{y}>\left[<\mathrm{w}^{\prime}, \mathrm{t}, \mathrm{y}>\in \operatorname{Dox}_{\mathrm{x}, \mathrm{w}, \mathrm{t}} \rightarrow \exists \mathrm{t}^{\prime \prime}\left[\mathrm{t}^{\prime}<_{\text {precedes }} \mathrm{t}^{\prime} \& \mathrm{y}\right.\right.$ becomes rich and famous in $\mathrm{w}^{\prime}$ at t”]]

Notice a parallel between the problem of the semantics of PC, and that of the future-orientation of a verb like expect. in both cases, the infinitive takes an argument that is non-identical to the relevant coordinate of the elements quantified over by the verb, but which stands in some systematic relationship to that coordinate. True, PC involves a part-whole relationship, while with futureoriented control predicates the relevant relationship is precedence. But since we are thinking of times as intervals rather than instants, they too can stand in non-trivial part-whole relations to one another: a time interval $t$ may be contained within a time interval of greater duration $t$ '.

These considerations reveal that if we model centred worlds as world-time-individual triples rather than world-individual pairs then we face a choice point concerning the semantics of partial control: PC could either be derived by shifting the individual coordinate of the centred worlds quantified over by the control verb, or by shifting the world-time-individual triples wholesale. The latter move would derive both a temporal shift (such as future-orientation) and the partial control effect in one fell swoop, via a semantics for the control predicate that induces existential quantification not over individuals or time intervals alone, but over world-time-individual triples taken as a unit. The revised semantics of expect would then be stated as follows:

\section{Lexical entry of expect: version 3}

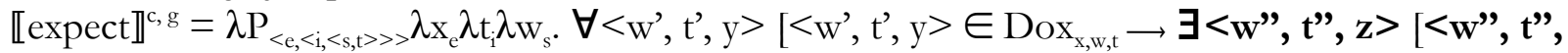
$z>$ is an extension of $\left.\left\langle w^{\prime}, t^{\prime}, y>\& P(z)\left(t^{\prime \prime}\right)\left(w^{\prime \prime}\right)\right]\right]$

This semantics depends on an 'extension' relation holding between world-time-individual triples $<w^{\prime}, t^{\prime}, y>$ and $<w^{\prime \prime}, t^{\prime \prime}, z>$. We define this relation in terms of the relations holding between pairs of coordinates of such triples: $:^{5}$

26. For any pair of world-time-individual triples $<\mathrm{w}, \mathrm{t}, \mathrm{x}>$ and $\left\langle\mathrm{w}^{\prime}, \mathrm{t}^{\prime}, \mathrm{y}\right\rangle,\left\langle\mathrm{w}^{\prime}, \mathrm{t}^{\prime}, \mathrm{y}\right\rangle$ is an extension of $<\mathrm{w}, \mathrm{t}, \mathrm{x}>$ iff for every $\alpha, \beta$ such that $\alpha$ is a coordinate of $<\mathrm{w}, \mathrm{t}, \mathrm{x}>$ and $\beta$ is a coordinate of $<\mathrm{w}$, t', $y>$ of the same type as $\alpha$, either.

(i) $\alpha \leqslant \beta$;

(ii) $\alpha<_{\text {precedes }} \beta$; or

(iii) $\beta<_{\text {precedes }} \alpha$

Let us examine how this definition works for each of the world, time interval and individual coordinates. World arguments of properties differ from temporal and individual arguments in the following way. A time interval $t$ may be a part of another time interval $t$ ', such that $t$ ' may saturate the temporal argument of a given property $P$. Likewise an individual $x$ may be a part of another individual $\mathrm{y}$, such that $\mathrm{y}$ may be the individual argument of $P$. But there is no entity $\mathrm{v}$ of which a world w may be a proper part, such that $P$ can take $\mathrm{v}$ as its world argument. Consequently, the world

\footnotetext{
5 The careful reader will notice that the definition of extension is too weak for the case of expect, since it fails to rule out the possibility of having expectations about the past rather than the future. We address this problem in the Appendix by defining different types of extension for different control predicates.
} 
coordinate of an extension of a centred world $<\mathrm{w}, \mathrm{t}, \mathrm{x}>$ must be itself. ${ }^{6}$ Given that if $\mathrm{w}=\mathrm{w}^{\prime}$, then w $\leqslant$ w', such a pair satisfies clause (i). On the other hand, time intervals and individuals may enter into non-trivial part-whole relationships. Let the part of relation ' $\leqslant$ ' be defined over both sets and plural individuals, the latter being objects constructed via the sum formation operator ' + '. Hence:

\section{The part of relation}

a. For any two sets $\mathrm{P}$ and $\mathrm{Q}, \mathrm{P} \leqslant \mathrm{Q}$ iff $\mathrm{P} \subseteq \mathrm{Q}$.

$\mathrm{b}$. For any two individuals $\mathrm{a}$ and $\mathrm{b}, \mathrm{a} \leqslant \mathrm{b}$ iff $\mathrm{a}+\mathrm{b}=\mathrm{b}$.

Clause (i) is also relevant to satisfying the definition of extension with respect to the individual coordinate: individuals are not the kinds of objects that can stand in precedence relations to one another. Thus $<w^{\prime}, t^{\prime}, y>$ is an extension of $<w, t, x>$ only if $x+y=y$. The possibility that the individual argument of the embedded property $\mathrm{x}$ is a superset of the doxastic centre $\mathrm{y}$ is responsible for the availability of partial control according to this view.

A glance at (27) reveals that in the case of time intervals, the extension relation can be satisfied in a greater range of circumstances than is the case for individuals. Recall that we are conceiving of time intervals as sets of instants. Thus the extension relation may be satisfied for a pair of time intervals $t$ and $t$ ' such that $t$ is a subset of t'. Additionally, clauses (ii) and (iii) offer the possibility that one time might stand in the precedence relation to the other. It is clear why this is not possible in the domain of individuals: these are not the kinds of objects that stand in precedence relations. In general, conditions that enter into determining what constitutes an extension are constrained by the relations that are made available by the logic that underpins the domain in question: part-whole structures feature in both the logic of time and the structure of the domain of individuals, whereas precedence relations figure in the former but not the latter.

Assuming the semantics for expect in (25), the interpretation of a partial control sentence like John expects to assemble in the hall is calculated as follows.

28a. John expects to assemble in the hall.

28b. [ [ [ ${ }_{\mathrm{CP} 1} \lambda \mathrm{t}_{1} \lambda \mathrm{w}_{2}\left[\mathrm{w}_{2} \mathrm{t}_{1}\right.$ John expects $\left[{ }_{\mathrm{CP} 2} \lambda \mathrm{x}_{3} \lambda \mathrm{t}_{4} \lambda \mathrm{w}_{5}\left[\mathrm{w}_{5} \mathrm{t}_{4} \mathrm{PRO}_{3}\right.\right.$ to assemble in the hall] $\left.\left.]\right]\right] \rrbracket=\lambda \mathrm{t} \lambda \mathrm{w}$. $\forall<w^{\prime}, t^{\prime}, y>\left[<w^{\prime}, t^{\prime}, y>\in \operatorname{Dox}_{\text {John,w, }} \longrightarrow \exists<w^{\prime \prime}, t^{\prime \prime}, z>\left[<w^{\prime \prime}, t^{\prime \prime}, z>\right.\right.$ is an extension of $<w^{\prime}, t^{\prime}, y>\& z$ assembles in the hall in w" at $\mathrm{t}$ "]]

We now have two possible ways of deriving partial control interpretations:

\section{The interpretation of partial control: the candidates}

I. Existential quantification over individuals of which the individual coordinate of a base world-timeindividual triple is a part.

II. Existential quantification over extensions of a base world-time-individual triple, where an extension is defined in terms of part-whole relations and precedence relations as in (26).

Schemas for the semantics of PC predicates corresponding to the two candidates are given below:

\footnotetext{
${ }^{6}$ A reviewer asks how this argument would play out in a situation semantics, where worlds have situations as parts. Since according to this view worlds are maximal situations it remains true that if $\langle$ w”, t”, $\mathrm{z}\rangle$ is an extension of $\langle$ w', t', $y\rangle$, then w" = w'. On the other hand, if attitude predicates are quantifiers over centred situations rather than centred worlds, as proposed by (Stephenson, 2010b) for imagine and remember, then in principle it should be possible for the definition of extension to be satisfied non-trivially for the situation/world coordinates. We leave it to future work to investigate whether PC predicates give rise to interpretations involving non-trivial part-whole relationships between situations.
} 
30. Lexical entry of a partial control predicate $C_{P C}$ : candidate I

$\llbracket C_{P C} \rrbracket^{\mathrm{c}, \mathrm{g}}=\lambda \mathrm{P}_{<\mathrm{e},<\mathrm{i},<\mathrm{s}, \mathrm{t}>>>} \lambda \mathrm{x}_{\mathrm{e}} \lambda \mathrm{t}_{\mathrm{i}} \lambda \mathrm{w}_{\mathrm{s}} . \forall<\mathrm{w}^{\prime}, \mathrm{t}^{\prime}, \mathrm{y}>\left[<\mathrm{w}^{\prime}, \mathrm{t}^{\prime}, \mathrm{y}>\in \mathbf{C}_{\mathrm{x}, \mathrm{w}, \mathrm{t}} \rightarrow \exists \mathrm{z}\left[\mathrm{y} \leqslant \mathrm{z} \& \mathrm{P}(\mathrm{z})\left(\mathrm{t}^{\prime}\right)\left(\mathrm{w}^{\prime}\right)\right]\right]$

Where $\mathbf{C}_{\mathrm{x}, \mathrm{w}, \mathrm{t}}$ is the set of x's $C$-alternatives in w at $\mathrm{t}$.

31. Lexical entry of a partial control predicate $C_{P C}$ : candidate II

$\llbracket C_{P C} \rrbracket^{c, g}=\lambda \mathrm{P}_{<\mathrm{e},<\mathrm{i},<\mathrm{s}, \mathrm{t}>>>} \lambda \mathrm{x}_{\mathrm{e}} \lambda \mathrm{t}_{\mathrm{i}} \lambda \mathrm{w}_{\mathrm{s}} . \forall<\mathrm{w}^{\prime}, \mathrm{t}^{\prime}, \mathrm{y}>\left[<\mathrm{w}^{\prime}, \mathrm{t}, \mathrm{y}>\in \mathbf{C}_{\mathrm{x}, \mathrm{w}, \mathrm{t}} \rightarrow \exists<\mathrm{w},, \mathrm{t}^{\prime \prime}, \mathrm{z}>\left[<\mathrm{w}, \mathrm{t}^{\prime \prime}, \mathrm{z}>\right.\right.$ is an extension of $<\mathrm{w}^{\prime}, \mathrm{t}^{\prime}, \mathrm{y}>\& \mathrm{P}(\mathrm{z})\left(\mathrm{t}^{\prime \prime}\right)(\mathrm{w}$ ')]]

Where for any pair of world-time-individual triples $<w, t, x>$ and $<w^{\prime}, t^{\prime}, y>,<w^{\prime}, t^{\prime}, y>$ is

an extension of $<\mathrm{w}, \mathrm{t}, \mathrm{x}>$ iff for every $\alpha, \beta$ such that $\alpha$ is a coordinate of $<\mathrm{w}, \mathrm{t}, \mathrm{x}>$ and $\beta$ is a coordinate of $<\mathrm{w}^{\prime}, \mathrm{t}$ ', $\mathrm{y}>$ of the same type as $\alpha$, either.

(i) $\alpha \leqslant \beta$; (ii) $\alpha<_{\text {precedes }} \beta$; or (iii) $\beta<_{\text {precedes }} \alpha$.

Candidate II depends crucially on the notion that the temporal coordinate of any centred world quantified over by an attitude predicate must be the subjective 'now' of the attitude holder. That is, it must be the time designated as the actual time according to what the attitude holder believes or what she says. This follows automatically for attitude predicates that quantify over doxastic alternatives such as expect as we have seen above. It also follows for attitude predicates that quantify over say-alternatives, as shown below for promise:

32. Candidate II-style semantics for promise:

$\llbracket$ promise $\rrbracket^{c, g}=\lambda P_{<e,<i,<s, t>>>} \lambda x_{e} \lambda t_{i} \lambda w_{s} . \forall<w^{\prime}, t^{\prime}, y>\left[<w^{\prime}, t^{\prime}, y>\in \operatorname{Say}_{x, w, t} \longrightarrow \exists<w^{\prime \prime}, t^{\prime \prime}, z>\left[<w^{\prime \prime}, t^{\prime \prime}, z>\right.\right.$ is an extension of $\left.\left.<\mathrm{w}^{\prime}, \mathrm{t}^{\prime}, \mathrm{y}>\& \mathrm{P}(\mathrm{z})\left(\mathrm{t}^{\prime \prime}\right)\left(\mathrm{w}^{\prime \prime}\right)\right]\right]$

Where $S_{a y, w, t}=\left\{<w^{\prime}, t^{\prime}, y>\right.$ : it is compatible with what $\mathrm{x}$ says in $\mathrm{w}$ at $\mathrm{t}$ for $\mathrm{x}$ to be $\mathrm{y}$ in $\mathrm{w}^{\prime}$ and for $\mathrm{t}$ to be $\left.\mathrm{t}^{\prime}\right\}$

What about PC predicates that quantify over some other modal base? Want, for instance, is standardly analyzed as a quantifier over buletic alternatives.

\section{Candidate II-style semantics for want:}

$\llbracket w a n t \rrbracket^{c, g}=\lambda P_{<e,<i,<s, t>>>} \lambda x_{e} \lambda t_{i} \lambda w_{s} . \forall<w^{\prime}, t^{\prime}, y>\left[<w^{\prime}, t^{\prime}, y>\in B_{x, w, t} \longrightarrow \exists<w ”, t^{\prime \prime}, z>\left[<w^{\prime \prime}, t^{\prime \prime}, z>\right.\right.$ is an extension of $\left.\left.<w^{\prime}, t^{\prime}, y>\& P(z)\left(t^{\prime \prime}\right)\left(w^{\prime \prime}\right)\right]\right]$

Where $\mathrm{Bul}_{\mathrm{x}, \mathrm{w}, \mathrm{t}}=\left\{\left\langle\mathrm{w}^{\prime}, \mathrm{t}^{\prime}, \mathrm{y}\right\rangle:\right.$ it is compatible with the fulfillment of $\mathrm{x}^{\prime} \mathrm{s}$ desires in $\mathrm{w}$ at $\mathrm{t}$ for $\mathrm{x}$ to be $y$ in w' and it is compatible with x's beliefs in w at $t$ for $t$ to be $t^{\prime}$ \}

With a buletic modal base, the world and individual coordinates are decoupled from the temporal coordinate: the attitude holder identifies individuals y she would like to be and worlds w' she would like to inhabit, but not times that she would like to be the actual time, but rather times t' that are candidates for the actual time. For example, Mary wants to go to the movies later reports roughly that for any such y and w', y goes to the movies in w' at some time later than Mary's subjective 'now'.

One could imagine more candidates that might be added to the list in (29), but this gives us plenty to work with for now. In this paper, we present arguments in favor of candidate II. We have already had a glimpse of one of these arguments: the discussion of expect suggested that by positing the same underlying mechanism - existential quantification over extensions of the elements quantified over by the predicate - the future-oriented interpretation of the verb and the availability of partial control could be derived at the same time. But this is a hunch based on a single predicate: the task of the next section is to identify the predictions that candidate II makes and check them against the facts. We will show that those predictions are borne out: in particular, candidate II 
proves to be successful in predicting for any given control predicate whether it belongs to the EC or the PC class, thereby solving one of the core problems for the theory of partial control.

\section{Predictions}

\section{$\underline{3.1 \text { Overview }}$}

This section identifies the predictions that our candidate analyses I and II make concerning which predicates license PC. Subsection 3.1 identifies a prediction that follows from both I and II, namely that only attitude predicates tolerate PC. We show that this prediction is borne out, suggesting that both candidates are along the correct lines. 3.2 concerns a prediction that follows from candidate II but not candidate I - namely, that there are no 'simultaneous' PC predicates: all PC predicates permit a shift in the time of the embedded event with respect to the matrix event, as already illustrated with future-oriented expect. This provides the beginning of an argument for candidate II. 3.3 strengthens this argument by showing that there are a small number of simultaneous attitudinal control predicates, and that these predicates belong to the EC class. This establishes that the connection between non-simultaneity and PC is not a coincidence, but rather calls for a principled explanation. Such an explanation can be provided by candidate II but not by candidate I.

\subsection{First prediction: attitude predicates}

So far our discussion has focused on what we have been calling 'attitude predicates': communication verbs or verbs of mental attitude. Under the heading 'communication verbs' are grouped not only speech act verbs such as say and claim, but all clause-embedding verbs that denote communicative acts. Vote and pretend are examples of verbs in this category: if I vote that Scotland should become independent, I communicate my desire for Scottish independence (in some legally sanctioned manner that results in this opinion being officially recorded), while if I pretend that I am a phonologist, then I behave in such a way as to falsely communicate that I am a phonologist.

Both of our candidate analyses of partial control predict that only attitude predicates can be partial control predicates. This is because they derive the partial control interpretation either via shifting of the individual coordinate of each centred world on its own, or by shifting all three coordinates in one fell swoop. A control verb that is not an attitude predicate is not a quantifier over centred worlds, and hence is incompatible with such a semantics.

To see this, let us briefly say something about the semantics of non-attitudinal control verbs. Notice that the idea that obligatorily controlled PRO is obligatorily abstracted over does not entail that all control verbs are quantifiers over centred worlds. Below we illustrate this with deserve.

34a. John deserves to become rich and famous.

34b. [CP1 $\lambda \mathrm{t}_{1} \lambda \mathrm{w}_{2}\left[\mathrm{w}_{2} \mathrm{t}_{1}\right.$ John deserves [ ${ }_{\mathrm{CP} 2} \lambda \mathrm{x}_{3} \lambda \mathrm{t}_{4} \lambda \mathrm{w}_{5}\left[{ }_{\mathrm{IP}} \mathrm{w}_{5} \mathrm{t}_{4} \mathrm{PRO}_{3}\right.$ to become rich and famous]]]] 34c. $\llbracket \mathrm{CP} 2 \rrbracket^{\mathrm{c}, \mathrm{g}}=\lambda \mathrm{x} \lambda \mathrm{t} \lambda \mathrm{w}$. $\mathrm{x}$ becomes rich and famous in $\mathrm{w}$ at $\mathrm{t}$

(34a) tells us nothing about John's mental state, and nor does it report any communicative act by John. Indeed, the subject of deserve need not be animate, as in This theory deserves careful scrutiny. Since inanimate individuals cannot be attitude holders, this is sufficient to establish that deserve is not an attitude predicate. We analyze it instead as a plain modal quantifier:

35. $\llbracket$ deserve $\rrbracket^{\mathrm{c}, \mathrm{g}}=\lambda \mathrm{P}_{<\mathrm{e},<\mathrm{i},<\mathrm{s}, \mathrm{t}>>>} \lambda \mathrm{x}_{\mathrm{e}} \lambda \mathrm{t}_{\mathrm{i}} \lambda \mathrm{w}_{\mathrm{s}} . \forall<\mathrm{w}^{\prime}, \mathrm{t}^{\prime}>\left[<\mathrm{w}^{\prime}, \mathrm{t}^{\prime}>\in \operatorname{Deserve}_{\mathrm{x}, \mathrm{w}, \mathrm{t}} \rightarrow \mathrm{P}(\mathrm{x})\left(\mathrm{t}^{\prime}\right)\left(\mathrm{w}^{\prime}\right)\right]$ 
Where Deserve $e_{x, w, t}=\left\{\left\langle w^{\prime}, t^{\prime}\right\rangle:\right.$ in $w^{\prime}$, at t', $x$ gets what $x$ deserves in $w$ at $\left.t\right\}$

This results in the following truth conditions for (34):

36. $\llbracket 34 \mathrm{~b} \rrbracket^{\mathrm{c}, \mathrm{g}}=\lambda \mathrm{t} \lambda \mathrm{w} . \forall<\mathrm{w}^{\prime}, \mathrm{t}^{\prime}>\left[<\mathrm{w}^{\prime}, \mathrm{t}^{\prime}>\in\right.$ Deserve $_{\text {John,w,t }} \rightarrow$ John becomes rich and famous in w' at t']

In this case, the elements quantified over by the control verb are less fine-grained than centred worlds, being simply world-time pairs. Consequently, the semantics does not introduce an individual coordinate that could be 'extended' to yield a partial control interpretation as we proposed in the last section. It is therefore correctly predicted that deserve is not a PC predicate:

37. *John deserves to assemble in the hall/go to the movies together.

Let us check that all PC predicates are attitude predicates. Here again is our list of the PC class:

\section{Partial control predicates}

glad, sad, regret, remember ${ }_{\mathrm{PC}}$, like, dislike, hate, loath, surprised, shocked, sorry, enjoy, imagine, deny, want, prefer, yearn, arrange, hope, afraid, refuse, agree, plan, aspire, decide, mean, intend, resolve, strive, demand, promise, choose, offer, eager, ready, wonder, ask, find out, interrogate, inquire, contemplate, deliberate, guess, grasp, understand, know, unclear, expect, vote, advise, recommend.

What diagnostic can we use to check that these are attitude predicates? Whereas the ability of deserve to combine with an inanimate subject shows that it is not an attitude predicate, the predicates in (38) all require animate subjects. This is not sufficient to show that they are all attitude predicates, only that it is in principle possible that they are. The diagnostic that we use instead is based on the consideration that only attitude verbs give rise to so-called 'double vision' puzzles. Consider the following scenario:

39. Scenario: 'There is a certain man in a brown hat whom Ralph has glimpsed several times under questionable circumstances on which we need not enter here; suffice it to say that Ralph suspects he is a spy. Also there is a grey-haired man, vaguely known to Ralph as rather a pillar of the community, whom Ralph is not aware of having seen except once at the beach. Now Ralph does not know it but the men are one and the same [Bernard Ortcutt].'

[(Quine, 1956): 56]

In this scenario, both of the following sentences (have readings on which they) are true, without the impression arising that Ralph has contradictory beliefs.

40a. Ralph believes that Ortcutt is a spy.

40b. Ralph believes that Ortcutt is not a spy.

This surprising state of affairs is usually explained by appeal to so-called 'acquaintance relations' ways in which an attitude holder is acquainted with some individual. In the 'double vision' scenario above, Ralph bears two acquaintance relations to Ortcutt - the 'saw in a brown hat' relation, and the 'saw at the beach' relation. (40a) is true in virtue of the fact that Ralph believes that the man he saw in a brown hat is a spy, and that man is Ortcutt. (40b) is true in virtue of the fact that Ralph believes 
that the man he saw at the beach is not a spy, and that man is Ortcutt. Only mental attitudes and communicative acts are mediated by acquaintance relations, and hence only attitude verbs give rise to double vision puzzles. To see this, let us add the following fact to the scenario in (39): it is Ralph's birthday, and he is considering who might come to his party. He is quite happy to welcome at the party anyone whom he considers a pillar of the community, but not a suspected spy. Thus both of the following sentences are judged true, without it following that Ralph is irrational:

41a. Ralph wants to welcome Ortcutt at the party.

41b. Ralph wants to snub Ortcutt at the party.

Now suppose that I am commenting on whom I think Ortcutt deserves to interact with at the party. I would contradict myself if I uttered the following sentences together:

42a. Ralph deserves to welcome Ortcutt at the party.

42b. Ralph deserves to snub Ortcutt at the party.

Unlike with believe and want, here it makes no difference that Ralph is in a state of 'double vision'.

Since deserve is not an attitude verb, the various acquaintance relations that Ralph bears to Ortcutt are irrelevant. This furnishes us with a test to distinguish between attitudinal and non-attitudinal control predicates: only the former give rise to double vision puzzles. Since space prevents us from

demonstrating that each of the predicates in the PC class passes this test, we will take as a sample the PC predicates introduced in the introduction: want, expect, vote and promise. Following the example we have already set with want, we will use expect, vote and promise to construct pairs of sentences, to be interpreted against the background of Quine's scenario.

Scenario: Ralph's expectation: "I will welcome the man I saw at the beach, and I will snub the man in the brown hat".

43a. Ralph expects to welcome Ortcutt at the party.

43b. Ralph expects to snub Ortcutt at the party.

Scenario: A vote is held on how various people should be received at a party. Ralph voted to welcome the man he saw at the beach, and to snub the man in the brown hat.

44a. Ralph voted to welcome Ortcutt at the party.

44b. Ralph voted to snub Ortcutt at the party.

Scenario: Ralph's promise: "I will welcome the man I saw at the beach, and I will snub the man in the brown hat."

45a. Ralph promised to welcome Ortcutt at the party.

45b. Ralph promised to snub Ortcutt at the party.

In (43), Ralph does not have contradictory expectations about what will happen at the party, while in (44) and (45) Ralph does not contradict himself with the reported communicative acts of voting and promising. We conclude that the partial control predicates want, expect, vote and promise are indeed attitude predicates. We leave it as an exercise to the reader to construct similar examples to demonstrate that the PC class consists entirely of attitude predicates.

In this subsection, we have shown that both of our candidates for the semantics of partial control correctly predict that all PC predicates are attitude predicates. We conclude that the idea that lies at the heart of these two implementations - that partial control arises by shifting of the individual 
coordinate of the elements quantified over by an attitude predicate (either on its own or by wholesale extension of the world-time-individual triples) - is along the right lines. In the next two subsections, we shall consider data that enable us to distinguish among our two candidates.

\section{$\underline{3.3 \text { Second prediction: non-simultaneity }}$}

The last subsection showed that both candidate analyses of partial control correctly predict that the PC class consists exclusively of attitude predicates. We now offer evidence in favor of candidate II. Here again for reference is a candidate II-style lexical entry for a partial control predicate:

46. Lexical entry of a partial control predicate $C_{P C}$ : candidate II

$\llbracket C_{P C} \rrbracket^{c, g}=\lambda \mathrm{P}_{<\mathrm{e},<\mathrm{i},<\mathrm{s}, \mathrm{t}>>>} \lambda \mathrm{x}_{\mathrm{e}} \lambda \mathrm{t}_{\mathrm{i}} \lambda \mathrm{w}_{\mathrm{s}} . \forall<\mathrm{w}^{\prime}, \mathrm{t}^{\prime}, \mathrm{y}>\left[<\mathrm{w}^{\prime}, \mathrm{t}^{\prime}, \mathrm{y}>\in \mathrm{C}_{\mathrm{x}, \mathrm{w}, \mathrm{t}} \rightarrow \exists<\mathrm{w}\right.$, $\mathrm{t}^{\prime \prime}, \mathrm{z}>\left[<\mathrm{w}^{\prime \prime}, \mathrm{t}^{\prime \prime}, \mathrm{z}>\right.$ is an extension of $\left.\left.<w^{\prime}, t^{\prime}, y>\& P(z)\left(t^{\prime \prime}\right)\left(w^{\prime \prime}\right)\right]\right]$

Where for any pair of world-time-individual triples $<w, t, x>$ and $<w^{\prime}, t^{\prime}, y>,<w^{\prime}, t^{\prime}, y>$ is an extension of $<\mathrm{w}, \mathrm{t}, \mathrm{x}>$ iff for every $\alpha, \beta$ such that $\alpha$ is a coordinate of $<\mathrm{w}, \mathrm{t}, \mathrm{x}>$ and $\beta$ is a coordinate of $<\mathrm{w}, \mathrm{t}$, $\mathrm{y}>$ of the same type as $\alpha$, either.

(i) $\alpha \leqslant \beta$; (ii) $\alpha<_{\text {precedes }} \beta$; or (iii) $\beta<_{\text {precedes }} \alpha$.

The property expressed by the complement of a PC predicate takes as its temporal argument a time interval t" that stands in a particular relation to t', the subjective 'now' of the attitude holder. Either (i) t' is a (possibly non-proper) part of t", (ii) t' precedes t", or (iii) t" precedes t'.

If all PC predicates follow the schema in (46), then no PC verb should impose a simultaneity requirement: all should tolerate an interpretation where either (i) the subjective 'now' is properly included in the time of the event described by the infinitive, (ii) the subjective 'now' precedes the time of the embedded event (future-orientation) or (iii) the event time precedes the subjective 'now' (past-orientation). We show that this prediction is borne out.

In fact, one of the insights of (Landau, 2000) is that the availability of future-oriented and past-oriented interpretations is intimately connected with the availability of PC. Following Landau, we diagnose whether a predicate licenses such interpretations by whether or not they tolerate temporal modifiers referring to mismatching times in the matrix and embedded clauses. A futureoriented predicate like expect permits yesterday to occur in the matrix with tomorrow in the embedded clause, while a past-oriented verb like remember licenses tomorrow in the matrix and yesterday downstairs:

47a. Yesterday John expected to go to the movies tomorrow.

47b. Tomorrow John will remember going to the movies yesterday.

Future- and past-oriented verbs make up a significant proportion of the PC class. Here is a sample:

\section{Future-oriented partial control predicates}

a. Yesterday John hoped/decided/planned/was eager/was ready to go to the movies tomorrow.

b. John hoped/decided/planned/was eager/was ready to go to the movies together.

\section{Past-oriented partial control predicates}

a. Tomorrow John will remember/regret going to the movies yesterday.

b. John remembered/regretted going to the movies together. 
This leaves us with a small group of partial control predicates that are neither future- nor past-oriented. These are the emotive factives listed in (50):

\section{Emotive factive partial control predicates}

glad, sad, like, dislike, hate, loath, surprised, shocked, sorry, enjoy

51a. John was glad/was sad/liked/disliked/hated going to the movies together.

51b. John liked/disliked/hated/loathed/enjoyed going to the movies together.

Here are some examples of intolerance of mismatching time adverbs by these predicates.

52a. *Yesterday John was glad/was sad/liked/disliked/hated to go to the movies tomorrow.

52b. *Yesterday John liked/disliked/hated/loathed/enjoyed going to the movies tomorrow.

53a. *Tomorrow John will be glad/be sad/like/hate to go to the movies yesterday.

53b. *Tomorrow John will like/dislike/hate/loath/enjoy going to the movies yesterday.

Nonetheless, Landau classed these verbs among those exhibiting what he treated as independent semantic tense in the complement clause, on the basis of data of the form of the following:

54a. Tomorrow John will be glad/be sad to have gone to the movies yesterday.

54b. Tomorrow John will like/dislike/hate/loath/enjoy having gone to the movies yesterday.

Yet the acceptability of these cases is compatible with a semantics where there is no quantification over extensions of centred worlds, and where the temporal argument is instead identical to the subjective 'now'. This is because in these examples the auxiliary have shifts the time of the embedded event to the past with respect to the attitude holder's 'now', thereby making the past-oriented adverb yesterday compatible with the future orientation of the matrix clause. So data such as Landau's do not show that the emotive factives are non-simultaneous in the sense that interests us here.

All is not lost, however. Our goal is to show that all PC predicates permit a nonsimultaneous interpretation in the sense that the time of the embedded predicate either (i) includes the subjective 'now', (ii) is later than the subjective 'now', or (iii) precedes the subjective 'now'. We have shown that emotive factives do not allow the future- or past-oriented interpretations of (ii) and (iii), but not that they fail to license a part-of relation between the subjective 'now' and the temporal argument of the embedded property. We will use temporal modifiers to show that the attitude holder's subjective 'now' may be properly included in the embedded event time.

Suppose emotive factives universally quantify over centred worlds $<w^{\prime}, t^{\prime}, y>$, and take a property type argument that is applied to some centred world $<w$ ", $t$ ", $z>$ such that (among other conditions), $t$ ' is properly included in $t^{\prime \prime}$. $t$ ' must then have shorter duration than $t$ ". It should therefore be possible to have a for-phrase $F$ in the matrix and a for-phrase $G$ in the embedded clause, such that $F$ requires the matrix event to be of a shorter duration than the duration of the embedded event given $G$. This is just what we find. Imagine that circumstances have forced John to spend a year living on a tight budget, after which time he can go back to living less frugally. The following sentences are possible ways of describing his reaction to such an experience. ${ }^{7}$

\footnotetext{
${ }^{7}$ An anonymous reviewer as well as consultants with whom I have discussed the examples remarked that combining surprised and shocked with a for-adverbial delimiting a relatively long duration may in general be dispreferred, for reasons independent of the topic of interest here. For these predicates, the contrast illustrated in (55) and (56) can be brought out by controlling for this confound by means of for-adverbials like for five minutes:
} 
55a. For two months, John was glad/was sad/surprised/shocked/sorry to live on a budget for a year (but then he got fed up with it).

55b. For two months, John liked/disliked/hated/loathed/enjoyed living on a budget for a year (but then he got fed up with it).

Strikingly, the reverse order of placement for the temporal adverbs is not allowed:

56a. *For a year, John was glad/sad/surprised/shocked/sorry to live on a budget for two months. 56b. *For a year, John liked/disliked/hated/loathed/enjoyed living on a budget for two months.

As with the mismatched temporal modifiers cases in (52)-(53), the examples in (56) are improved by adding have, but that is not the point: we are interested in the interpretive options that the lexical semantics makes available without the contribution of overt markers.

The second piece of evidence for the non-simultaneity of emotive factives concerns their ability to tolerate non-stative embedded predicates. ${ }^{8}$ We use an achievement predicate as an example:

57a. John was glad/was sad/surprised/shocked/sorry to reach the summit.

57b. John liked/disliked/hated/loathed/enjoyed reaching the summit.

Setting aside enjoy, all of the predicates in (57) are stative. ${ }^{9}$ Given the set up we are assuming, a stative simultaneous predicate is expected not to tolerate an eventive predicate in its complement. To see why, recall that for such a predicate, the subjective 'now' of the attitude holder is identical to the embedded event time. We also assume that stative predicates have the subinterval property:

\section{The subinterval property}

A tenseless sentence $\phi$ has the subinterval property iff the truth of $\phi$ with regard to some interval $t$ guarantees the truth of $\phi$ with regard to all the subintervals of $t$.

[(Ogihara, 2007): 399, ex 17, based on (Bennett \& Partee, 1972; Taylor, 1977; Vlach, 1981)]

Thus if Mary is sick at $t$, then she is sick at all subintervals of $t$. If at $t$ John was glad to reach the summit then at all subintervals of $\mathrm{t}$ John was glad to reach the summit. We assume that $x$ is glad $P$ presupposes that $\mathrm{x}$ believes $P$ and asserts that $\mathrm{x}$ wants $P$ - that is, that $P$ is true at all of $\mathrm{x}$ 's buletic alternatives $<\mathrm{w}^{\prime}, \mathrm{t}, \mathrm{y}>{ }^{10}$ If glad were a simultaneous predicate, then $P$ would take t' (x's subjective 'now') as its temporal argument. So John is glad to reach the summit uttered at $\mathrm{t}$ would assert that for all of John's buletic alternatives at $\mathrm{t},<\mathrm{w}$ ', t', $\mathrm{y}>$, y reaches the summit at t' in w'. By (58), this should entail that all subintervals of $t t^{\prime \prime}$ are such that for all of John's buletic alternatives at $t$ ", $<w$ ', $t$ "', $y>$, $y$ reaches the summit at $t$ "' in w'. If $t$ ' is the subjective 'now' of the attitude holder at $t$, and $t$ "' is the

Context: A short meeting has been scheduled on a Sunday morning.

(i) For five minutes, John was surprised/shocked to be in a meeting for ten minutes on a Sunday morning.

(ii) *For ten minutes, John was surprised/shocked to be in a meeting for five minutes on a Sunday morning.

${ }^{8}$ The use of eventive predicates to diagnose (non-)simultaneity has a long history (Abusch, 2004; Boskovic, 1996, 1997;

Enc, 1991; Martin, 1996, 2001; Pesetsky, 1992; Wurmbrand, 2011). However, if the arguments described in this paper concerning the distribution of eventive predicates in infinitives is correct, then the only simultaneous predicates that are expected to prohibit eventive predicates are the statives and claim. As shown in section 3.4, pretend is a simultaneous predicate but nonetheless licenses eventive infinitives.

${ }_{9}^{9}$ Because enjoy is not stative, the argument from eventive predicates does not apply to this verb. We nonetheless assign it the same semantics as the other emotive factives, on the basis of the facts concerning for-adverbials.

${ }^{10}$ A complete semantics for glad is provided in the Appendix. 
subjective 'now' of the attitude holder at some subinterval of $t \mathrm{t}$ ", then $t$ "' is a subinterval of $t$ '. So John is glad to reach the summit should entail that reach the summit holds not only at John's subjective 'now', but also at any subinterval of John's subjective 'now'. But this requirement cannot be fulfilled: an accomplishment can only be true at $\mathrm{t}$ if it is false at all subintervals of $\mathrm{t}$ (see (Ogihara, 2007) for discussion).

The same line of reasoning can be used to explain the inability of exceptional case marking believe to embed a bare eventive predicate, noted in (Abusch, 2004; Wurmbrand, 2014): ${ }^{11}$

59a. *John believed Mary to reach the summit.

59b. John believed Mary to be reaching the summit.

Thus the ability of stative emotive factives like glad to embed non-stative predicates like reach the summit would be unexpected if like believe these are simultaneous predicates. Is a solution to this puzzle provided by the idea that these predicates permit the embedded predicate to take as temporal argument a time that includes the attitude holder's subjective 'now'? Readers familiar with the literature on tense and aspect may have noticed that the incorporation of existential quantification over times that include the subjective 'now' of the attitude holder in the candidate II semantics is akin to building the semantics of the progressive into the meaning of the relevant verbs. Consider the following semantics for the progressive, based on (Bennett \& Partee, 1972): ${ }^{12}$

\section{0. $\llbracket P R O G \rrbracket^{c, g}=\lambda \phi_{<i,<s, t>>} \lambda t_{i} \lambda w_{s^{*}} . \exists t^{\prime}: t \subset t^{\prime} \& \phi\left(t^{\prime}\right)(w)$}

This semantics states that the progressive existentially quantifies over times t' that properly include some base time argument $t$, and requires that the property with which it combines be true of t'. We are proposing that the semantics of emotive factives more or less replicates this effect by introducing existential quantification over an object that contains a temporal coordinate - a centred world. As is well known, the addition of progressive marking enables eventive predicates to occur in environments where they would otherwise be disallowed, such as English present tense sentences:

61a. *John reaches the summit.

61b. John is reaching the summit.

If as we are proposing emotive factives have a progressive-like meaning component, their ability to embed eventive predicates is expected.

We have shown that candidate II correctly predicts that all PC predicates tolerate interpretations where the embedded event takes place at a time that includes, is later than or is earlier

\footnotetext{
${ }^{11}$ We illustrate the idea with an achievement predicate, but the point can also be made with an activity predicate such as dance, or an accomplishment predicate such as build a house. Dance must be construed habitually when embedded in its bare form below believe:

(i) John believed Mary to dance (*at that moment).

Activity predicates lack the subinterval property (Taylor, 1977; Dowty, 1977, 1979). Consequently, the requirement that

(i) entails that in each of John's belief worlds, 'Mary dances' holds at every subinterval of John's subjective 'now' is not satisfied.

Likewise, in its bare form, build a house is ungrammatical (or perhaps marginally allows a habitual reading):

(ii) *John believed Mary to build a house.

This too is due to the fact that the embedded predicate lacks the subinterval property.

12 This semantics sets aside Bennett and Partee's condition that the original interval be a non-final subinterval of the shifted one.
} 
than the subjective 'now'. We should also consider how candidate I fares with respect to the data discussed in this section. Here is a reminder of the candidate I-style semantics:

\section{Lexical entry of a partial control predicate $C_{P C}$ : candidate $I$ \\ $\llbracket C_{P C} \rrbracket^{c, g}=\lambda \mathrm{P}_{<\mathrm{e},<\mathrm{i},<\mathrm{s}, \mathrm{t}>>>} \lambda \mathrm{x}_{\mathrm{e}} \lambda \mathrm{t}_{\mathrm{i}} \lambda \mathrm{w}_{\mathrm{s}} . \forall<\mathrm{w}^{\prime}, \mathrm{t}^{\prime}, \mathrm{y}>\left[<\mathrm{w}^{\prime}, \mathrm{t}^{\prime}, \mathrm{y}>\in \mathbf{C}_{\mathrm{x}, \mathrm{w}, \mathrm{t}} \rightarrow \exists \mathrm{z}\left[\mathrm{y} \leqslant \mathrm{z} \& \mathrm{P}(\mathrm{z})\left(\mathrm{t}^{\prime}\right)\left(\mathrm{w}^{\prime}\right)\right]\right]$}

According to this lexical entry, the property expressed by the infinitive is applied to an individual that includes the doxastic centre of the attitude holder, but the time and world arguments remain untouched. This yields the PC effect, but it makes no predictions about the temporal properties of partial control predicates. This is not to say that it is in principle incompatible with the behavior of PC predicates with respect to the temporal properties observed in this section and in Landau's work. One could yield these effects by defining covert tense or aspect operators that occur in the complements of the relevant verbs. This type of approach is found in both the syntactic and semantic literature on the temporal properties of infinitives (see for example (Abusch, 2004; Wurmbrand, 2014). But if we were to adopt it we would lack an explanation of the correlation between the ability to license a PC reading and tolerance of non-simultaneous interpretations. After all, if partial control can be derived by such a simple semantics as that given in (62), why should its distribution be restricted to environments that license embedding of covert temporal operators? A semantics that derives both PC and non-simultaneous interpretations via the same mechanism, thereby eliminating the need to say anything more about embedded tense and offering insight into the conditions under which predicates can tolerate partial control, seems preferable.

The argument can be made stronger still by showing that there are attitudinal control predicates that fail to license non-simultaneous interpretations, and that such predicates belong to the exhaustive control class. The existence of such predicates would be a mystery for candidate I, but unsurprising if we adopt candidate II. To put it another way, the data discussed so far are compatible with the possibility that, perhaps for reasons that are not directly related to partial control, all attitudinal control predicates license non-simultaneous readings. We could then simply say that in order to belong to the PC class, it is necessary and sufficient for the control verb to be an attitude predicate, without discussing temporal issues. The case for candidate II will therefore be stronger if we can show that there is no necessary connection between being an attitude predicate and licensing non-simultaneous readings. This is the goal of the next sub-section.

\section{$\underline{3.4 \text { Simultaneous attitudinal control predicates }}$}

This sub-section provides evidence that there are attitudinal control predicates that only license simultaneous interpretations, and that these verbs belong to the EC class. The semantics of these predicates requires the property expressed by the infinitive to take as its time argument the temporal coordinate of the centred worlds universally quantified over by the verb. The embedded event therefore takes place at the subjective 'now'. From the perspective of candidate II, this means that the semantics of this class of attitude predicate does not appeal to extensions of centred worlds. Since on this view, existential quantification over extensions is what yields the possibility of PC, these verbs are predicted to belong to the EC class. Here we provide a template of the semantics that simultaneous attitudinal control predicates are expected to have.

\section{Semantics of simultaneous attitudinal control predicates from the candidate II point of view}

For any simultaneous attitudinal control predicate $C_{\text {sim-ats }}$

$\llbracket C_{\text {sim-att }} \rrbracket^{\mathrm{c}, \mathrm{g}}=\lambda \mathrm{P}_{<\mathrm{e},<\mathrm{i},<\mathrm{s}, \mathrm{t}>>>} \lambda \mathrm{x}_{\mathrm{e}} \lambda \mathrm{t}_{\mathrm{i}} \lambda \mathrm{w}_{\mathrm{s}} . \forall<\mathrm{w}^{\prime}, \mathbf{t}^{\prime}, \mathrm{y}>\left[<\mathrm{w}^{\prime}, \mathbf{t}^{\prime}, \mathrm{y}>\in \mathbf{C}_{\mathrm{x}, \mathrm{w}, \mathrm{t}} \rightarrow \mathrm{P}(\mathrm{y})\left(\mathbf{t}^{\prime}\right)\left(\mathrm{w}^{\prime}\right)\right]$ 
There seem to be only two attitudinal control predicates in English that belong to the EC class: pretend and claim. In fact, an area of disagreement between this paper and Landau's work is that he classifies claim as a PC predicate, on the basis of examples like the following:

64a. The chair claimed to be gathering once a week. [(Landau, 2000): 30, ex 8c]

64b. The chair claimed to have gathered last week.

65a. (Mary said that) John claimed to be living together.

65b. (Mary said that) John claimed to have lived together.

We agree that these are examples of acceptable PC sentences with claim. But notice that they become unacceptable with the bare infinitive, without overt tense or aspect marking (66a), whereas the EC variant of the sentence is perfect (66b):

66a. *(Mary said that) John claimed to live together.

66b. Mary and John claimed to live together.

This is a striking contrast with true partial control predicates, which require no overt tense or aspect markers in order to license PC. We therefore class claim as an EC predicate, modulo the observation that it is unlike other EC predicates in that it can permit PC under special circumstances. The following data show that pretend patterns with claim, and we shall therefore treat it the same way:

67a. The chair pretended to be gathering once a week.

67b. The chair pretended to have gathered last week.

68a. (Mary said that) John pretended to be living together.

68b. (Mary said that) John pretended to have lived together.

69a. *(Mary said that) John pretended to live together.

69b. Mary and John pretended to live together.

We will show that while pretend and claim differ in their behavior owing to their distinct aspectual characteristics, their differing behavior provides convergent evidence that they are both simultaneous predicates, and that in this respect they are quite different animals from PC predicates.

We start with pretend. We will show that the time interval argument of a property expressed by the complement of the verb must be identical with the subjective 'now'. This means that this time cannot (i) include the subjective 'now', (ii) be included in the subjective 'now', (iii) be in the future with respect to the subjective 'now', or (iv) be in the past with respect to the subjective 'now'.

We saw in the discussion of emotive factives that a control verb whose complement may describe an event that takes place at a time that properly includes the subjective 'now' of the attitude holder can be diagnosed by tolerance of the co-occurring phrases for two months in the matrix and for a year in the embedded clause. Pretend disallows this configuration:

70. *For two months, John pretended [to live on a budget for a year].

To check whether the complement of pretend may have an event time that is included in the subjective 'now' of the attitude holder, we simply need to reverse the order of the for-phrases: 
71. *For a year, John pretended [to live on a budget for two months].

The usual tests show that pretend does not tolerate a future-oriented or past-oriented interpretation:

72a. *Yesterday John pretended to go to the movies tomorrow.

72b. *Tomorrow John will pretend to go to the movies yesterday.

Again, mismatching temporal modifiers can be licensed if we adopt Landau's strategy of embedding bave in the infinitive:

73. Tomorrow John will pretend to have gone to the movies yesterday.

However, this is compatible with the property expressed by the infinitive taking the subjective 'now' as its temporal argument: have shifts the time back from the subjective 'now', making it possible for tomorrow and yesterday to co-occur. That an overt aspectual marker is needed in order to accomplish this strengthens our case that pretend has the semantics of a simultaneous predicate.

Let us now turn to claim. The test for future- or past-orientation yields the same results as for pretend. However, the test must be applied with care: claim does not tolerate eventive predicates in its complement, as discussed in (Abusch, 2004; Pesetsky, 1992; Wurmbrand, 2014). Thus a counterpart of (72a) with pretend replaced with claim is ungrammatical even when shorn of the temporal adverbs:

74. *John claimed to go to the movies.

We shall therefore replace the eventive predicate go to the movies with the stative be sick:

75. John claimed to be sick.

Now we can replicate the result we found with pretend: with the embedded predicate in its bare form, claim does not tolerate mismatching temporal adverbs in the matrix and infinitival clauses:

76a. *Yesterday John claimed to be sick tomorrow.

76b. *Tomorrow John claimed to be sick yesterday.

The investigation of claim is complicated further by the fact that in the absence of overt aspectual marking, the verb does not license a for-phrase in its complement. This means that our mismatching for-phrase test cannot be applied with this verb.

77. *John claimed to be sick for a year.

We therefore need another way to show that claim does not permit the subjective 'now' to be included in the time interval argument of the embedded property. Our argument comes from the inability of claim to license eventive predicates in the embedded clause. We shall show that the assumption that claim is a simultaneous predicate provides an account of this observation.

Let us assume that claim is indeed a simultaneous predicate, which by (63) entails that it has the following lexical entry:

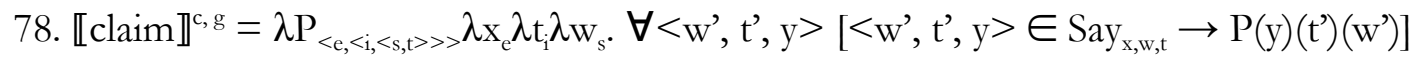


We continue to assume that control complements lack semantically contentful tense, so that a control sentence where claim embeds a stative predicate has the following LF and truth conditions:

79a. John claims to be sick.

79b. [ ${ }_{\mathrm{CP} 1} \lambda \mathrm{t}_{1} \lambda \mathrm{w}_{2}\left[{ }_{\mathrm{IP} 1} \mathrm{w}_{2} \mathrm{t}_{1}\right.$ John claims $\left[{ }_{\mathrm{CP} 2} \lambda \mathrm{x}_{3} \lambda \mathrm{t}_{4} \lambda \mathrm{w}_{5}\left[{ }_{\mathrm{IP} 2} \mathrm{w}_{5} \mathrm{t}_{4} \mathrm{PRO}_{3}\right.\right.$ to be sick $\left.\left.\left.]\right]\right]\right]$

79c. [CP2 $\rrbracket^{c, g}=\lambda x \lambda t \lambda w . x$ is sick in $w$ at $t$

79d. $\llbracket C P 1 \rrbracket^{c, g}=\lambda t \lambda w . \forall<w^{\prime}, t^{\prime}, y>\left[<w^{\prime}, t^{\prime}, y>\in S_{a_{\text {John,w,t }}} \rightarrow \mathrm{y}\right.$ is sick in w' at t']

Here are the computations for the example in (74), which is degraded unless a habitual interpretation is assigned to the embedded predicate.

80a. $*{ }_{\mathrm{CP} 1} \lambda \mathrm{t}_{1} \lambda \mathrm{w}_{2}\left[{ }_{\mathrm{IP} 1} \mathrm{w}_{2} \mathrm{t}_{1}\right.$ John claims $\left[{ }_{\mathrm{CP} 2} \lambda \mathrm{x}_{3} \lambda \mathrm{t}_{4} \lambda \mathrm{w}_{5}{ }_{[\mathrm{IP} 2} \mathrm{w}_{5} \mathrm{t}_{4} \mathrm{PRO}_{3}\right.$ to go to the movies]]]]

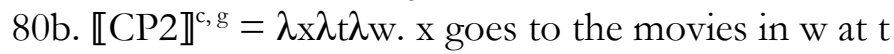

80c. [CP1 $\rrbracket^{c, g}=\lambda t \lambda w . \forall<w^{\prime}, t^{\prime}, y>\left[<w^{\prime}, t^{\prime}, y>\in S_{\text {John,w,t }} \rightarrow\right.$ y goes to the movies in w' at t']

In (80), the subjective 'now' is the time that John takes to be the time at which his utterance is taking place. Utterances are events that take place at a certain time, which is typically of short duration, but which has a part-whole structure (it is longer than a moment). A general requirement on utterance events is that the uttered sentence be true throughout the time at which the utterance take place. Evidence for this comes from the requirement that present tense sentences be stative; the main predicate must either be stative, or be 'stativized' by the use of progressive morphology. The only way to ensure that a sentence holds throughout the time at which it is uttered, is if it has the subinterval property - which is to say that it must be stative. Hence Mary goes to the movies is ungrammatical (apart from on its habitual reading), but Mary is going to the movies is acceptable (see Ogihara 2007 for overview).

This property of utterance events is reflected in the semantics of verbs that report such events, like claim. Suppose that t' is John's subjective 'now' - the time that he takes to be 'now' at the time of the reported utterance event. Whatever John is saying on the occasion in question should be the kind of thing that can be true throughout t'. The sentence that John is reported to have uttered should therefore have the subinterval property. Since go to the movies lacks the subinterval property, it cannot in its bare form be embedded by claim. This is responsible for the ungrammaticality of (80).

If claim permitted the subjective 'now' to be included in the time interval argument of the embedded property - if claim were not a simultaneous predicate - the inability of this verb to embed eventive predicates would be mysterious. This would amount to building a progressive-like meaning into the semantics of claim, as we did with the emotive factives. John claims to go to the movies would be predicted to require that there be a time interval that includes John's subjective 'now' such that John goes to the movies at $t$. Whenever there is such a time interval, it is also the case that for any time t' that is included in John's subjective 'now', there is a time $t$ that includes t' such that John goes to the movies at $\mathrm{t}$. The requirement that the event described by the embedded predicate hold throughout the time that John takes to be the utterance time would then be satisfied, and the inability of claim to embed eventive predicates would be unexplained. We conclude that claim is a simultaneous predicate: it has neither a future-oriented, past-oriented or progress-like meaning.

We have shown that candidate II correctly predicts that in the basic case, claim and pretend fail to license PC. What should we make of the improvement of PC with progressive aspect and auxiliary have? Recall that we proposed that the semantics of PC predicates incorporates the semantic effects of progressive marking in the case of emotive factives, and past marking in the case of pastoriented control predicates. The examples above seem to suggest that overt progressive and past 
tense can perform the same role. ${ }^{13}$ We leave it to future work to explain why the distribution of these variants of the progressive and the past tense is constrained to complements of attitudinal control predicates, and to find the most appropriate statement of the semantics of these elements.

\section{Consequences of the theory}

\section{$\underline{4.1 \text { Overview }}$}

This section shows that our theory provides answers to the three core questions about partial control: what determines whether a given control predicate falls into the PC or EC class; why partially controlled PRO behaves in some ways like it is plural and in other ways like it is singular; why there is no 'partial raising'.

\subsection{Predicting membership of the PC class}

We have already made progress towards showing that a theory of PC based on the notion of an extension of the centred worlds quantified over by the verb makes correct predictions concerning membership of the PC class. Section 3.2 showed that the theory correctly predicts that all partial control predicates are attitude predicates, while section 3.3 showed that it correctly predicts that all PC predicates license non-simultaneous interpretations, and 3.4 showed that it correctly predicts that obligatorily simultaneous attitudinal control predicates do not license PC (modulo the addition of overt tense or aspect markers). Call these two characteristics of the PC class properties (i) and (ii) respectively. In the best case, properties (i) and (ii) would be not only necessary conditions for membership of the PC class, but also sufficient conditions. This would mean that our theory provides a complete answer to the question of what determines whether a given predicate licenses PC, without appeal to auxiliary assumptions. In this sub-section, we show that this is indeed the case by providing evidence that no member of the EC class exhibits both properties (i) and (ii).

Let us remind ourselves which predicates belong to the EC class.

\section{Exhaustive control predicates}

try, dare, manage, make sure, bother, remember $_{\mathrm{EC}}$, get, see fit, condescend, avoid, forget, refrain, decline, neglect, force, compel, fail, begin, start, continue, finish, stop, resume, have, need, may, should, is able, must, deserve, claim, pretend.

We have seen already that deserve is not a quantifier over centred worlds and is therefore correctly predicted to license exhaustive control exclusively. The other modals can be given an analogous treatment. Aspectual verbs too are not attitudinal. If they were, they would be expected to give rise to double vision puzzles, contrary to what we find:

82a. \#Ralph began to welcome Ortcutt and (at the same moment) Ralph began to snub Ortcutt. 82b. \#Ralph started to welcome Ortcutt and (at the same moment) Ralph started to snub Ortcutt.

${ }^{13}$ Comments from a reviewer persuaded us that auxiliary have in the complement of claim and pretend marks past tense rather than perfective aspect. (Landau, 2000) notes that have in this environment is compatible with punctual time adverbials, unlike perfective have. The contrast between (ii) and (iii) suggests that have is perfective in the scope of manage; this may be responsible for why PC is not ameliorated in this environment.

(i) John has finished his duties (*at $5 \mathrm{pm}$ ).

(ii) John claimed/pretended to have finished his duties at $5 \mathrm{pm}$.

(iii) John managed to have finished his duties (*at $5 \mathrm{pm}$ ) 
82c. \#Ralph continued to welcome Ortcutt and (at the same moment) Ralph continued to snub Ortcutt.

82d. \#Ralph finished welcoming Ortcutt and (at the same moment) Ralph finished snubbing Ortcutt.

82e. \#Ralph stopped welcoming Ortcutt and (at the same moment) Ralph stopped snubbing Ortcutt.

82f. \#Ralph resumed welcoming Ortcutt and (at the same moment) Ralph resumed snubbing Ortcutt.

What about implicatives? Consider try. Evidence for the non-simultaneity of try comes from its tolerance of temporal modifiers that denote mismatched durations:

83. John tried for a month to live on a budget for a year.

We therefore cannot appeal to simultaneity to explain why try falls into the EC class. Perhaps it is not an attitude predicate? Its meaning certainly appears to incorporate an attitude - namely intention. Intuitively, if John tried to become rich and famous, then he did something with the intention that he become rich and famous. (Just what he did is left open.) If the notion of intention is a component of the meaning of try, then we should expect to find double vision puzzles arising with pairs of control sentences constructed from this verb. Let us go back to Ralph's birthday party. Suppose that Ralph has formed the intention to make Ortcutt (the man he saw at the beach) feel welcome, and to snub him (the man in the brown hat). Now let us suppose that he is currently acting on these intentions, say by playing a piece of music that he thinks that the man he saw at the beach likes, but the man in the brown hat hates. In such a situation, both of the following sentences are true, without it following that Ralph is irrational:

84a. John is trying to welcome Ortcutt at the party.

$84 \mathrm{~b}$. John is trying to snub Ortcutt at the party.

This is an argument that try is an attitude predicate. Given that it is also a non-simultaneous predicate, we seem to have a counterexample to our hypothesis that properties (i) and (ii) are jointly necessary and sufficient conditions for membership of the PC class.

But try is no ordinary attitude predicate. (Sharvit, 2003) noticed that unlike canonical attitude predicates such as believe and want, try produces infelicity when it embeds an existential DP that does not refer to any object in the actual world. This is revealed by the following contrast:

85a. \#John tried to ride a unicorn.

85b. John wanted to ride a unicorn.

The contrast is surprising: if attitude predicates quantify over worlds (and times and individuals) compatible with an agent's mental state, there ought to be no requirement that sentences in which they occur carry entailments about the existence of mentioned individuals in the actual world. (Sharvit, 2003) and (Grano, 2011) respond to this challenge by offering a semantics for try whereby it is not a quantifier over centred worlds. Such a semantics is sufficient to rule out partial control.

The other implicatives are simultaneous predicates:

86a. *Yesterday, John dared/today, John is daring to go to the movies tomorrow.

86b. *Today, John is daring/tomorrow, John will dare to go to the movies yesterday. 
86c. *Last April John dared for a month to live on a budget for a year.

87a. *Yesterday, John managed/today, John is managing to go to the movies tomorrow.

87b. *Today, John is managing/tomorrow, John will manage to go to the movies yesterday.

87c. *Last April John managed for a month to live on a budget for a year.

The inability of these predicates to license partial control follows straightforwardly.

The discussion in this subsection suggests that our statement of the conditions for

membership of the PC class is essentially correct, but is in need of the following slight amendment:

88. Licensing partial control

A control predicate $C$ is a partial control predicate iff:

(i) it is a canonical attitude predicate and

(ii) it licenses non-simultaneous interpretations.

\section{Canonical attitude predicate}

A predicate is a canonical attitude predicate iff it is a universal quantifier over centred worlds.

Here for reference is a table summarizing the correlation between the conditions in (i) and (ii) and the availability of PC that we have observed with the control predicates discussed in this paper.

\begin{tabular}{|l|l|l|l|}
\hline Predicate & $\begin{array}{l}\text { (i) Canonical attitude } \\
\text { predicate? }\end{array}$ & $\begin{array}{l}\text { (ii) Non- } \\
\text { simultaneous? }\end{array}$ & EC/PC class \\
\hline $\begin{array}{l}\text { expect, remember, } \\
\text { glad, ... }\end{array}$ & Yes & Yes & PC \\
\hline claim, pretend & Yes & No & EC (modulo PROG, have) \\
\hline try, deserve & No & Yes & EC \\
\hline
\end{tabular}

We have established that our analysis of partial control makes correct predictions about which control predicates belong to the EC class, and which to the PC class.

\section{$\underline{4.3 \text { Explaining 'syntactic singularity' }}$}

(Landau, 2000) treated PC PRO as syntactically singular and semantically plural. The underlying intuition was that with respect to syntactic properties, PC PRO behaves as though it were singular, and with respect to semantic properties, it behaves like a plurality. This is part of the puzzle: why can the understood subject combine with a collective predicate, but not license a plural anaphor? Our proposal points towards an answer to this question that does not resort to a distinction between syntactic and semantic number features. Consider (90):

90. *John intends to meet each other in the hall.

Why does PRO fail to license the reciprocal, even in the scope of a PC predicate? We shall assume that the syntax only permits a reciprocal to be licensed by a subject that bears the feature [plural]:

91. The students/*The student met each other in the hall. 
Furthermore, we shall assume that there is no distinction between syntactic and semantic plurality. Contra (Landau, 2000), there are just the phi-features [singular] and [plural]. [Singular] introduces a presupposition that the noun with which it combines has atomic denotation (Heim, 2007; Sauerland, 2003). The explanation for the ungrammaticality of (90) must then be that partially controlled PRO bears [singular], despite the fact that it can combine with a collective predicate.

If partially controlled PRO with a singular antecedent bears [singular], then it is just like any other occurrence of PRO in that it inherits its phi-features from its controller, as can be diagnosed by observing the phi-features on an anaphor that it binds: ${ }^{14} 15$

92a. I intended/tried to distinguish myself at the conference.

92b. You intended/tried to distinguish yourself at the conference.

92c. She intended/tried to distinguish herself at the conference.

92d. We intended/tried to distinguish ourselves at the conference.

92e. You(pl.) intended/tried to distinguish yourselves at the conference.

92f. They intended/tried to distinguish themselves at the conference.

But if partially controlled PRO with a singular antecedent also bears [singular], what permits it to combine with a collective predicate? Our account provides a ready answer to this question. PRO does not denote an individual but is merely a bound variable. As such, its [singular] feature is deleted at LF under the rule 'Feature Deletion Under Semantic Binding':

\section{Feature deletion under semantic binding}

Delete the features to all variables that are semantically bound.

(von Stechow, 2003)

The question, then, is not whether PRO is singular or plural, but rather whether the property expressed by the infinitive is applied to an atomic or a plural individual. One way that the latter scenario may come about is if the infinitive or gerund is introduced by a predicate whose semantics appeals to the notion of an extension, the individual coordinate of which may be a plurality. This explains the apparent tension between the singular-like and plural-like behavior of PC PRO.

\section{$\underline{4.4 \text { No partial raising }}$}

There is no partial raising: sentences such as the following are ungrammatical. ${ }^{16}$

94a. *John seems (to Mary) to live together.

94b. *John is likely to go on vacation together.

94c. *John appears (to Mary) to be a team.

The question of why likely does not permit partial raising can be quickly disposed of: it is not an attitude predicate, but rather a plain modal like possible or probable. Consequently, the notion of extension that is crucial to our semantics for partial control is inapplicable. On the other hand, seem

\footnotetext{
14 (Rodrigues, 2007) provides further evidence that partially controlled PRO inherits phi-features from the controller, based on agreement with epicene nouns in Romance.

15 A reviewer points out that the question of how PRO comes to inherit the controller's phi-features remains illunderstood on the property view. We have nothing new to offer concerning this question, but merely assume that data like (90) and Rodrigues' data are convincing evidence that PRO does indeed inherit the controller's phi-features.

${ }^{16}$ For discussion, see for example (Landau, 2000). (Bowers, 2008) expresses skepticism about the idea that there is no partial raising, but the contrast between the examples in (94) and their PC counterparts seems quite clear.
} 
and appear could be treated as attitudinal: the attitude holders in these cases are provided by the Experiencer argument. Here is a toy semantics for an example with seem to illustrate this point. ${ }^{17}$

95a. John seems to Mary to like her $\mathrm{r}_{\mathrm{i}} / *$ herself $_{\mathrm{i}}$.

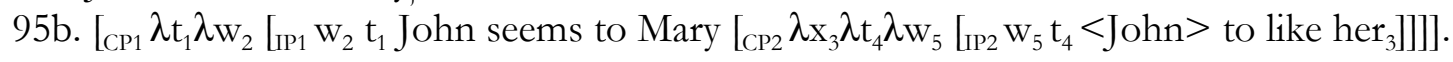

96. 【seem $\rrbracket^{c, g}=\lambda \mathrm{P}_{<\mathrm{e},<\mathrm{i},<\mathrm{s}, \mathrm{t}>>>} \lambda \mathrm{x}_{\mathrm{e}} \lambda \mathrm{t}_{\mathrm{i}} \lambda \mathrm{w}_{\mathrm{s}} . \forall<\mathrm{w}^{\prime}, \mathrm{t}^{\prime}, \mathrm{y}>\left[<\mathrm{w}^{\prime}, \mathrm{t}^{\prime}, \mathrm{y}>\in \operatorname{Seem}_{\mathrm{x}, \mathrm{w}, \mathrm{t}} \rightarrow \mathrm{P}(\mathrm{y})\left(\mathrm{t}^{\prime}\right)\left(\mathrm{w}^{\prime}\right)\right]$

Where $\operatorname{Seem}_{\mathrm{x}, \mathrm{w}, \mathrm{t}}=\left\{\left\langle\mathrm{w}^{\prime}, \mathrm{t}^{\prime}, \mathrm{y}^{\prime}\right\rangle\right.$ : it is compatible with what seems to $\mathrm{x}$ to be the case in $\mathrm{w}$ at $\mathrm{t}$ for $\mathrm{x}$ to be $\mathrm{y}$ in $\mathrm{w}^{\prime}$ and for $\mathrm{t}$ to be $\mathrm{t}^{\prime}$ \}

97a. $\llbracket C P 2 \rrbracket^{c, g}=\lambda x \lambda t \lambda w$. John likes $x$ at $t$ in $w$

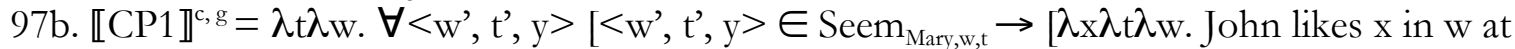
$\left.\mathrm{t}](\mathrm{y})\left(\mathrm{t}^{\prime}\right)\left(\mathrm{w}^{\prime}\right)\right]=\forall<\mathrm{w}^{\prime}, \mathrm{t}^{\prime}, \mathrm{y}>\left[<\mathrm{w}^{\prime}, \mathrm{t}^{\prime}, \mathrm{y}>\in \operatorname{Seem}_{\text {Mary }, \mathrm{w}, \mathrm{t}} \rightarrow\right.$ John likes $\mathrm{x}$ in w' at t']

According to this analysis, seem is like attitudinal control predicates in being a quantifier over centred worlds, and it therefore takes an argument of property type. As usual, the individual argument of this property is the individual coordinate of the elements quantified over by the matrix verb - the doxastic centre. In control, the doxastic centre is associated with the understood subject in virtue of the fact that PRO is abstracted over and the doxastic centre is supplied as the individual argument of the resulting property. But not so with raising. We have highlighted this by inclusion in the infinitive of an overt pronoun corresponding to the Experiencer of seem. If this pronoun is interpreted de se, then it will be abstracted over, yielding a property that, as in control, takes the doxastic centre as its individual argument. But this means that the doxastic centre is associated with the overt pronoun, not with the understood subject. In fact, the doxastic centre cannot be associated with the understood subject, as shown by the inability of the understood subject to bind herself in (95a).

This is the crucial difference between control and raising from which the impossibility of partial raising follows. Even if we were to find a non-simultaneous, attitudinal raising predicate, existential quantification over extensions of the elements quantified over by this predicate would not affect the interpretation of the understood subject. Suppose for the sake of argument that the semantics of seem did indeed appeal to extensions. Still (94a) would be ungrammatical:

98a. *John seems to Mary to live together.

98b. [CP1 $\lambda \mathrm{t}_{1} \lambda \mathrm{w}_{2}\left[{ }_{\mathrm{IP} 1} \mathrm{w}_{2} \mathrm{t}_{1}\right.$ John seems to Mary [ ${ }_{\mathrm{CP} 2} \lambda \mathrm{x}_{3} \lambda \mathrm{t}_{4} \lambda \mathrm{w}_{5}\left[{ }_{\mathrm{IP} 2} \mathrm{w}_{5} \mathrm{t}_{4}<\right.$ John $>$ to live together]]]]. 98c. [CP2 $\rrbracket^{c, g}=\lambda x \lambda+\lambda w$. John lives together in $w$ at $t$

98d. $\lambda$ t $\lambda$ w. $\forall<w^{\prime}, t^{\prime}, y>\left[<w^{\prime}, t^{\prime}, y>\in \operatorname{Seem}_{\text {Mary,w,t }} \rightarrow \exists<w^{\prime \prime}, t^{\prime \prime}, z>\left[<w^{\prime \prime}, t ”, z>\right.\right.$ is an extension of $<\mathrm{w}^{\prime}, \mathrm{t}, \mathrm{y}>\&[\lambda \mathrm{x} \lambda \mathrm{t} \lambda \mathrm{w}$. John lives together in $\mathrm{w}$ at $\left.\left.\mathrm{t}](\mathrm{z})\left(\mathrm{t}^{\prime \prime}\right)(\mathrm{w} ")\right]\right]=$

17 One of the details that is glossed over here is that if seem is an attitude verb, then strictly speaking John should be construed de re. We have abstracted away from this in order to keep the LF reasonably simple. We continue to assume the standard analysis of de re interpretations by appeal to an acquaintance relation holding between the attitude holder and the res; the target truth conditions in this case can be paraphrased as 'There is some acquaintance relation $\mathrm{R}$ between Mary and John such that for each of Mary's seem-alternatives < $w^{\prime}, t^{\prime}, y>$, the individual to whom y bears R in w' assembles in the hall in w' at t'. This paraphrase reveals that while it looks as though we should have vacuous binding in (98b), a complete LF would provide an individual variable for the individual abstractor to bind. We have retained the individual variable in our computations in order to facilitate comparison between the representations for raising and control. Note that with a raising sentence that does not embed a de se or a de re expression, such as It seems to be raining, a variant of seem that embeds a propositional, rather than property-type complement should be assumed. Vacuous binding is thus avoided in such cases. 
$\lambda t \lambda w . \forall<w^{\prime}, t^{\prime}, y>\left[<w^{\prime}, t^{\prime}, y>\in \operatorname{Seem}_{\text {Mary, w, }} \rightarrow \exists<w^{\prime \prime}, t^{\prime \prime}, z>\left[<w^{\prime \prime}, t^{\prime \prime}, z>\right.\right.$ is an extension of $<w^{\prime}, t^{\prime}$, $\mathrm{y}>\&$ John lives together in w" at t']]

In general, in order for any attitude predicate that takes an infinitival complement to license a subset-superset relationship between the antecedent and the understood subject, any doxastic centre $\mathrm{y}$ to which the property expressed by the infinitive is applied must be designated by the attitude holder's mental state as (a superset of) the counterpart of whatever individual $\mathrm{x}$ is denoted by the antecedent of the understood subject. That is, y (or an individual that includes y) must be among the attitude holder's candidates for $\mathrm{x}$. Attitudinal raising verbs lack this property. The core syntactic difference between raising and control verbs is that raising establishes a dependency between two Apositions, only one of which is occupied by a DP bearing a theta-role, whereas in control, both controller and PRO have distinct theta-roles. This property of raising verbs precludes the attitude holder from being the antecedent of the understood subject: in such a configuration, the attitude holder would be an Experiencer, while the understood subject would be assigned whatever theta role was appropriate given the embedded predicate. Consequently, there can be no partial raising.

\subsection{An objection: PC with object control verbs}

It is worth spending a little time over the idea discussed in the last subsection that the possibility of partial control depends on a doxastic centre $y$ being one of the attitude holder's candidates for some individual $\mathrm{x}$, where $\mathrm{x}$ is the denotation of the antecedent of the understood subject. With a two-place predicate, this is just a way of saying that $y$ is one of the attitude holder's candidates for herself: since the predicate only takes one nominal argument the attitude holder and the controller must be one and the same. However, an anonymous reviewer points out that with three-place predicates, the roles of controller and attitude holder may be fulfilled by different DPs:

99a. John advised Mary to read his paper carefully.

99b. John recommended to Mary to read his paper carefully.

With verbs of communication like advise and recommend the attitude holder is the agent of the communicative act - the subject in these case. Yet the controller is the object:

100. John ${ }_{\mathrm{i}}$ advised/recommended Mary ${ }_{\mathrm{j}}\left[\mathrm{PRO}_{*_{\mathrm{i}} / \mathrm{j}}\right.$ to listen to $*$ himself $_{\mathrm{i}} /$ herself $_{\mathrm{j}}$ carefully].

What is predicted concerning PC in these cases? We said in the last subsection that PC is only available if any individual argument to which the property expressed by the embedded clause applies is identical to or properly includes an individual that is designated by the attitude holder's mental state (or communicative act) as a candidate for the individual denoted by the controller. Given our set-up, this amounts to saying that for any individual x denoted by the controller of a control verb $C$, $C$ must quantify over centred worlds $<w^{\prime}, t^{\prime}, y>$ such that it is compatible with the attitude holder's mental state (or communicative act) for $\mathrm{x}$ to be $\mathrm{y}$ in $\mathrm{w}^{\prime}$ at t'. Since controller and attitude holder are non-identical with advise and recommend, we seem to predict that these verbs do not license PC.

All of this assumes, however, that there can only be one doxastic centre. What if, instead, some attitude predicates were quantifiers over tuples consisting of a world, a time and two individuals, $<w^{\prime}, t^{\prime}, x^{\prime}, y^{\prime}>$ ? Three-place attitude verbs would be good candidates for lexical items of 
this type: we would then have one individual coordinate per nominal argument. ${ }^{18}$ To illustrate, the advise-alternatives quantified over by advise would be defined as follows:

101. Advise $e_{x, y, w, t}=\left\{<w^{\prime}, t^{\prime}, x^{\prime}, y^{\prime}>\right.$ : $x^{\prime} s$ advice to $y$ in $w$ at $t$ is fulfilled in $w^{\prime}$ and it is compatible with $x^{\prime}$ s beliefs in $w$ at $t$ for $x$ to be $x^{\prime}$ and $y$ to be $y^{\prime}$ and $t$ to be $\left.t^{\prime}\right\}$

On its object control use, advise is a universal quantifier over these tuples. It takes a property-type argument obtained by abstraction over PRO in the usual way, along with two individual arguments:

\section{Lexical entry of advise: first version}

$\llbracket$ advise $\rrbracket^{c, g}=\lambda y \lambda P \lambda x \lambda t \lambda w . \forall<w^{\prime}, t^{\prime}, x^{\prime}, y^{\prime}>\left[<w^{\prime}, t^{\prime}, x^{\prime}, y^{\prime}>\in \operatorname{Advise}_{x, y, w, t} \rightarrow P\left(y^{\prime}\right)\left(t^{\prime}\right)\left(w^{\prime}\right)\right]$

If this is correct, then object control does not after all replicate the situation with raising: here there are two doxastic centres, and one of these supplies the individual argument of the embedded property. With advise, the individual in question is not a candidate of the subject's for herself, but rather a candidate of the subject's for the addressee of her communicative act. The doxastic centre that supplies the individual argument of the property expressed by the embedded clause is thus associated with the object rather than the subject of advise, as the following example illustrates.

103a. John advises Mary to listen carefully.

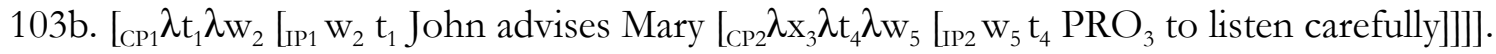

103c. $\llbracket C P 2 \rrbracket^{c, g}=\lambda x \lambda t \lambda w . x$ listens carefully in $w$ at $t$

103d. $\lambda \mathrm{t} \lambda$ w. $\forall<\mathrm{w}^{\prime}, \mathrm{t}^{\prime}, \mathrm{x}^{\prime}, \mathrm{y}^{\prime}>\left[<\mathrm{w}^{\prime}, \mathrm{t}^{\prime}, \mathrm{x}^{\prime}, \mathrm{y}^{\prime}>\in\right.$ Advise $_{\text {John,Mary,w,t }} \rightarrow \mathrm{y}^{\prime}$ listens carefully in $\mathrm{w}^{\prime}$ at $\left.\mathrm{t}^{\prime}\right]$

What does this predict about about licensing of partial control with an object control predicate such as advise? We have said that a PC predicate must be an attitude predicate, as advise is. Furthermore, from raising we learned that the embedded property must take as an argument the (or an) individual coordinate y of the centred worlds quantified over by the predicate (or some individual that includes y). Our semantics guarantees that advise has both properties. If in addition it has the non-simultaneity property, then it is predicted to be a PC predicate. The following examples show that advise does indeed tolerate mismatching temporal modifiers (103a) and partial control (103b).

104a. Yesterday John advised Mary to listen carefully at the lecture tomorrow.

104b. John advised Mary to work on the project as a team.

This subsection has shown that our account predicts that an object control verb that designates the subject as the attitude holder and satisfies the non-simultaneity condition will license PC providing that it is a quantifier over doubly centred worlds. This was exemplified with advise, whose semantics is given in its final version below.

105. Lexical entry of advise: final version

$\llbracket$ advise $\rrbracket^{c, g}=\lambda y \lambda P \lambda x \lambda t \lambda w . \forall<w^{\prime}, t^{\prime}, x^{\prime}, y^{\prime}>\left[<w^{\prime}, t^{\prime}, x^{\prime}, y^{\prime}>\in\right.$ Advise $_{x, y, w, t} \rightarrow \exists<w ”, t^{\prime \prime}, x^{\prime \prime}, y^{\prime \prime}>\left[<w^{\prime \prime}\right.$, $t^{\prime \prime}, x^{\prime}, y^{\prime \prime}>$ is an extension of $\left.\left.<w^{\prime}, t^{\prime}, x^{\prime}, y^{\prime}>\& P\left(y^{\prime \prime}\right)\left(t^{\prime \prime}\right)\left(w^{\prime \prime}\right)\right]\right]$

18 The use of doubly centred worlds for communication verbs provides a means of accounting for the observation that with object control with such verbs, PRO is interpreted 'de te', meaning that the subject must think of the object as the addressee of her speech act (Schlenker, 1999). For further applications of this idea see (Uegaki, 2011), which uses it as the basis for a solution to the puzzle of controller shift. 
An anonymous reviewer raises two open issues concerning our account of partial object control. Firstly, the analysis assumes that there is a means of ensuring that the controller is the object rather than the subject: if doubly centred worlds are invoked, then one must specify which of the two centres is the argument of the property obtained by abstracting over PRO. ${ }^{19}$ In a simple case such as (103) there is no de se pronoun corresponding to the subject, and it follows from the lexical entry for advise in (105) that the individual argument of the property expressed by the infinitive is (or includes) the center associated with the object rather than the subject. Matters are more complicated with an overt de se pronoun for the subject, as in (106).

106. Sue ${ }_{i}$ advised Mary to listen to her ${ }_{i}$ carefully.

Here, a second lexical entry for advise will be needed, which treats the embedded clause as expressing a relation between the two centres. Both PRO and the overt pronoun will be bound, and the order of abstraction and of application of the two individual arguments will have to be specified so that the reading 'Sue advised Mary that Sue should listen to Mary carefully' is ruled out. I take it that this is a general issue for doubly centred worlds accounts; a complete solution should also take into account the relationship of controller shift to doubly centred worlds discussed in (Uegaki 2011).

A related question concerns the possibility of assigning a partial control-like interpretation to an overt de se pronoun in the complement of an object control verb. What prevents (106) from being assigned the meaning 'Sue advised Mary to listen to a group including Sue carefully'? One way to rule this out is by modifying (105) so that only the addressee centre is shifted. However it is difficult to see a principled reason why the subject centre should not also be shifted, given that a theme of this paper is the possibility of shifting all coordinates of a centred world wholesale. We leave these matters for future research.

\section{Further issues}

\section{$\underline{5.1 \text { Comparison with other proposals }}$}

\subsection{1 (Landau, 2000)}

An important similarity between our proposal and that in (Landau, 2000) is that both tie the availability of PC to temporal properties of the verb. It is therefore useful to compare the analyses. ${ }^{20}$

Landau claims that all PC verbs tolerate mismatching temporal adverbials like yesterday and tomorrow in the main and embedded clauses, and that EC verbs lack this property. From this he concludes that the complements of PC predicates are tensed, while the complements of EC predicates are untensed. He attempts to derive the existence of partial control from this generalization, together with the assumption that DPs bear a semantic number feature [SP], with partially controlled PRO being syntactically singular and semantically plural.

Landau assumes that the crucial difference between a tensed and an untensed infinitive is that T-Agr (the phi-features associated with $\mathrm{T}$ ) raises to $\mathrm{C}$ in the former but stays in situ in the latter. With untensed (EC) predicates, an Agree relation is established between a matrix functional head ( $\mathrm{T}$ for subject control, $v$ for object control) and PRO, but with tensed (PC) predicates, Agree is between the functional head and T-Agr in its displaced position in C. T-Agr winds up higher than

\footnotetext{
${ }^{19}$ This point was also raised by Yasutada Sudo (p.c.).

${ }^{20}$ While we focus here on (Landau, 2000), further contributions to the literature on partial control are found in (Landau, 2003, 2004, 2006, 2008, 2010, 2013b).
} 
PRO, preventing PRO from entering into an Agree relation with matrix T or v. T-Agr may optionally bear a semantic plurality feature, valued by agreement with a lexical DP. That is, if the DP with which it agrees bears [+SP], it too bears [+SP]. If it is [-SP], T-Agr remains as [ØSP], which is assumed to be non-distinct from the negative value of this feature on a functional head. In this circumstance, a partial control configuration results if $\mathrm{PRO}$ is selected from the lexicon bearing $[+\mathrm{SP}]$. The intervention of T-Agr for the purposes of Agree permits the controller and PRO to bear different values of the semantic plurality feature, giving rise to the PC interpretation.

A problem with this view is that, as we have seen in this paper, there are EC predicates such as try and deserve that allow mismatching matrix and embedded event times. Furthermore, (Grano, 2012) shows that the EC verb have to also passes the mismatching temporal modifiers test:

107. (When I asked to see the manager,) they told me I had to come back tomorrow.

$$
\text { [(Grano, 2012): 195, ex 27] }
$$

By making the availability of PC depend on whether the predicate is a quantifier over worldtime-individual triples, our account avoids these problems. On the other hand, much of the data discussed in this paper lend support to Landau's insight that the possibility of PC is closely connected to the temporal properties of the control verb. The notion of an 'extension' of the elements quantified by over the verb provides a principled account of why this should be.

\subsubsection{Syntactic vs. semantic theories of partial control}

Space constraints prevent us from offering a critique of the many syntactic analyses of partial control on the market; the reader is referred to (Landau, 2013a) for discussion. Instead, we will discuss some data that cast doubt on the prospects of formulating an explanation for the existence of partial control in purely syntactic terms.

Examples involving a distributive marker in the matrix clause and an embedded collective predicate are grammatical with PC predicates (108a) but not with EC predicates (108b), even though the counterparts of (108b) without each are grammatical (108c).

108a. The students each wanted/expected/voted/promised to assemble in the hall. 108b. *The students each tried/managed/dared to assemble in the hall.

108c. The students tried/managed/dared to assemble in the hall.

Whatever syntactic resources are employed to let the controller be a subset of the understood subject in PC will be inadequate to deal with these cases: the issue here is not a subset/superset relationship between controller and understood subject: (108a) is naturally understood with understood subject and antecedent being identical. The question, which our account offers an answer to, is why each should make a difference. We assume that each has the semantics in (109).

109. $\llbracket$ each $\rrbracket^{c, g}=\lambda P \lambda x . \forall y[A T(y) \& y \leqslant x \rightarrow P(y)]$

Each combines with a predicate $\mathrm{P}$ and an individual $\mathrm{x}$ to yield truth just in case every atomic subpart of $\mathrm{x}$ is P. (108a) is true just in case wanted PRO to assemble in the hall is true of every individual student. Thus while (108a) does not look like PC from a syntactic point of view, the calculation of the truth conditions involves partial control, since the property of wanting to assemble in the hall is applied to 
an atomic individual. (108a) says that for every student $x$, for each of $x$ 's buletic alternatives $<w$ ', t', $y>$ there is an extension of $\left\langle w^{\prime}, t^{\prime}, y>,<w ", t\right.$ ', $z>$ such that $z$ assembles in the hall in $w^{\prime \prime}$ at $t^{\prime \prime} .^{21}$

\subsection{The nature of extensions}

Our proposal makes crucial reference to an extension relation holding between pairs of centred worlds. Here as a reminder is the definition of this notion.

\section{Extension}

For any pair of world-time-individual triples $<\mathrm{w}, \mathrm{t}, \mathrm{x}\rangle$ and $\left.\left\langle\mathrm{w}^{\prime}, \mathrm{t}^{\prime}, \mathrm{y}\right\rangle,<\mathrm{w}^{\prime}, \mathrm{t}^{\prime}, \mathrm{y}\right\rangle$ is an extension of $<w, t, x>$ iff for every $\alpha, \beta$ such that $\alpha$ is a coordinate of $<w, t, x>$ and $\beta$ is a coordinate of $<w^{\prime}, t^{\prime}$, $\mathrm{y}>$ of the same type as $\alpha$, either.

(i) $\alpha \leqslant \beta$;

(ii) $\alpha<_{\text {precedes }} \beta$; or

(iii) $\beta<{ }_{\text {precedes }} \alpha$

Things could certainly have been otherwise. Consider the following three possibilities that in principle the grammar might have made available, but which the data discussed in this paper suggest are ruled out: (1) The extension relation could hold between individual coordinates rather than world-time-individual triples; (2) Clause (i) of (110) could be the only way for the extension relation to be satisfied; (3) A fourth clause, ' $\beta \leqslant \alpha$ ' could be added.

Option (1) is simply our candidate I semantics, which we have argued is less successful empirically than candidate II. Option (2) would mean that $\left\langle w^{\prime}, t^{\prime}, y>\right.$ is not an extension of $<w, t$, $\mathrm{z}>$ if $\mathrm{t}$ precedes $\mathrm{t}$ ' or vice versa. This would incorrectly predict that future- and past-oriented predicates are not partial control predicates. Option (3) would incorrectly predict the existence of 'inverse partial control', where the controller denotes a superset of the understood subject:

111. *The committee ${ }_{\mathrm{i}}$ decided $\mathrm{PRO}_{\mathrm{i} \text { - }}$ to wear a t-shirt.

$$
\text { [(Landau, 2000): 66, 106d] }
$$

Option (3) would also wrongly predict that there are PC predicates that permit an interpretation where the time of the embedded event is included in the time of the matrix event. Such predicates would tolerate for a year in the matrix and for a month in the embedded clause - a combination that we saw in section 3.4 is impossible with emotive factives. In sum, the facts show that while one could imagine variants of our proposal employing one of the implementations in (1-3), the grammar does not make any of these options available. In this section we discuss what to make of this finding.

Notice that the array of relations that according to the definition in (110) may hold between coordinates $\alpha$ and $\beta$ in order to satisfy the extension relation is exactly those that are needed to predict the range of temporal properties exhibited by the non-simultaneous attitudinal control predicates. Emotive factives appeal to clause (i), future-oriented predicates to clause (ii), and past-

${ }^{21}$ An anonymous reviewer drew our attention to the following interesting example:

(i) The students each wanted to visit one another.

(We have used one another rather than each other since our informants tell us that the variant of (i) with each other is degraded due to an impression of redundancy created by repetition of each.) The semantics of matrix each requires the predicate wanted to visit one another to be distributed over atomic members of the set of students, while embedded one another is required by the syntax to have a subject that bears the feature [plural]. Our account predicts that this should be possible with PC predicates but not with EC predicates. The prediction appears to be borne out:

(ii) *The students each tried to visit one another. 
oriented predicates to clause (iii). It seems that the existence of future- and past-oriented predicates is what rules out option (2). Likewise, the non-existence of predicates that permit the embedded event time to be included in the matrix event time rules out option (3). We suggest that if there were such a verb, we would also expect to find 'inverse progressive' extensions: the existence of such a verb would introduce another way that a pair of time or individual coordinates may satisfy the extension relation, which would in turn generate the possibility of inverse PC.

It seems, then, that the derivation of partial control is parasitic upon the derivation of nonsimultaneous interpretations. While the array of relations that may satisfy the definition of extension are exactly those that are needed to derive non-simultaneous interpretations, it includes a relation temporal precedence - that is redundant in the domain that is relevant to partial control, since individuals cannot stand in precedence relations to one another. The question then, is why the availability of partial control should depend on the availability of non-simultaneous readings: that is, why there cannot be a partial control predicate with a candidate I-style semantics.

The answer may lie in the fact that it is inherent to the meaning of non-simultaneous predicates that they have the temporal orientation that they have. An intention would not be an intention if it concerned something I have already done, rather than something I am about to do. Similarly, I cannot remember something that is yet to happen. By contrast, partial control is in some sense a 'secondary' property of the predicates that permit it. My intention to go to the movies tonight is an intention regardless of whether I will do so alone, or with friends.

One could get by, then, with an intend that does not license PC, but not with one that does not have a future-orientation. The minimum task of the grammar is therefore to generate nonsimultaneous readings for configurations that lack contentful tense in the embedded clause.

Confining our attention to attitudinal control predicates, there are in principle a number of possible ways that this could come about. One option is to shift only the temporal coordinate of the centred worlds quantified over by the verb; another is to shift all three coordinates wholesale. If the latter is chosen, then as an epiphenomenon, the verb will permit partial control. The idea that partial control is a side effect of some other mechanism sits well with the observation that its grammatical status lies somewhat on the margins: speakers vary in the degree to which they find partial control acceptable. It may be that in the grammars of speakers who reject partial control, non-simultaneity is derived simply by shifting the temporal coordinate of the centred worlds quantified over by nonsimultaneous control verbs, rather than by shifting all three coordinates wholesale. Yet other speakers might have one type of lexical entry for some partial control predicates, and the other type for others. This might account for the gradability that White and Grano (2013) find in acceptability judgments for partial control. By contrast, we will never find a speaker for whom intend licenses partial control but not future-orientation: such a speaker simply would not know the meaning of intend.

\subsection{Implications for the semantics of control}

What are the consequences of our account for theories of the semantics of control in general? We began with a discussion of the property view, according to which PRO is bound by an abstractor in the left periphery of the infinitive. We then showed that contrary to the claim in (Landau, 2000), the existence of partial control is compatible with the property view. But does our analysis show that the property view is preferable to other theories of the semantics of control?

We address this question by comparing the property view with a family of theories that also predict the obligatorily de se interpretation of PRO in the scope of attitude predicates - namely, theories that treat attitude verbs as inducing 'context shift'. A context is a tuple consisting of a world, time and speaker/author, and takes the form of a parameter on the interpretation function. 
Its role is to supply denotations for indexicals like $I$, now and actually by identifying the speaker, time and world of utterance. Interpretation is further relativized to an index - a world-time pair - which enables the truth value of a sentence to be determined by providing access to the relevant facts that hold at that world and time. Here for example is the lexical entry for the first person pronoun:

112. $\llbracket I \rrbracket^{c, g}=$ author $(\mathrm{c})$

Notice that contexts have the same type as centred worlds - they are world-time-individual triples. This observation provides the starting point for theories of de se that treat attitude predicates as quantifiers over contexts rather than centred worlds (Schlenker, 1999; Schlenker, 2003). In this setup, the role of doxastic centre is fulfilled by the individual coordinate of a context - the author.

An argument for this view is provided by languages such as Amharic, Slave and Zazaki where the denotation of an indexical can shift in the scope of an attitude predicate (Anand \& Nevins, 2004; Anand, 2006; Schlenker, 1999; Schlenker, 2003). In such languages, an embedded first person pronoun need not denote the author of the actual context:
113. Heseni
$\left(\mathrm{m} \dot{\mathrm{t}}_{\mathrm{k}}-\mathrm{ra}\right) \quad \mathrm{va}$
$\mathrm{k} \varepsilon \quad \varepsilon z_{\mathrm{j} / \mathrm{k}} \quad \mathrm{d} \boldsymbol{\varepsilon}$ wletia
Hesen.OBL (I.OBL-to) said that I rich.be-PRES
Hesen said that $\{\mathrm{I}$ am, Hesen is $\}$ rich
[Zazaki, (Anand \& Nevins, 2004): 21, ex 4]

(Schlenker, 2003) analyzes such cases by treating attitude verbs as quantifiers over contexts, thereby letting them shift the author coordinate with respect to which a first person indexical is evaluated:

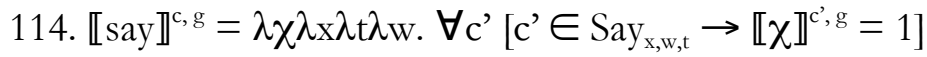
Where $\mathrm{Say}_{\mathrm{x}, \mathrm{w}, \mathrm{t}}=\left\{\mathrm{c}^{\prime}\right.$ : it is compatible with what $\mathrm{x}$ expects in $\mathrm{w}$ at $\mathrm{t}$ for $\mathrm{x}$ to be author $\left(\mathrm{c}^{\prime}\right)$ in $\operatorname{world}\left(\mathrm{c}^{\prime}\right)$ at time $\left.\left(\mathrm{c}^{\prime}\right)\right\}$

115. $\llbracket$ Hesen $_{\mathrm{i}}$ says that $\mathrm{I}_{\mathrm{i}}$ am rich $\rrbracket^{\mathrm{c}, \mathrm{g}}=\lambda \mathrm{t} \lambda \mathrm{w} . \forall \mathrm{c}^{\prime}\left[\mathrm{c}^{\prime} \in \mathrm{Say}_{\mathrm{Hesen}, \mathrm{w}, \mathrm{t}} \rightarrow \llbracket \mathrm{I}\right.$ am rich $\left.\rrbracket^{\mathrm{c}^{\prime}, \mathrm{g}}=1\right]$

$=\lambda \mathrm{t} \lambda \mathrm{w} . \forall \mathrm{c}^{\prime}\left[\mathrm{c}^{\prime} \in \mathrm{Say}_{\mathrm{Hesen,w}, \mathrm{t}} \rightarrow\right.$ author $\left(\mathrm{c}^{\prime}\right)$ is rich in world $\left(\mathrm{c}^{\prime}\right)$ at time $\left.\left(\mathrm{c}^{\prime}\right)\right]$

Within this framework, PRO can be analyzed without appeal to abstraction operators in the syntax by treating it as having its value supplied by the author coordinate of a (shifted) context: ${ }^{22}$

116. $\llbracket P R O \rrbracket^{c, g}=$ author $(\mathrm{c})$

117a. John expected to become rich and famous.

117b. John expected [ $\mathrm{CP}$ PRO to become rich and famous].

117c. $\llbracket \mathrm{CP} \rrbracket^{\mathrm{c}, \mathrm{g}}=$ author $(\mathrm{c})$ becomes rich and famous in world(c) at time(c).

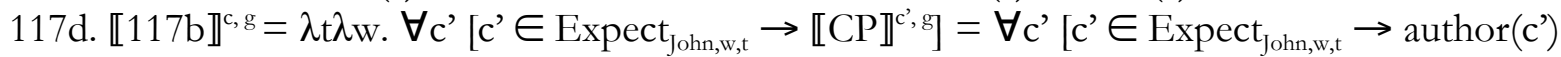

becomes rich and famous in world $\left(c^{\prime}\right)$ at time $\left.\left(c^{\prime}\right)\right]$

\footnotetext{
22 I thank an anonymous reviewer for pointing out that a second lexical entry would be needed for object control; here, PRO should denote the addressee of the context. As the reviewer points out, the need to multiply the entries for PRO, and concomitantly to supply an account of the distribution of the two variants of PRO in subject versus object control, is a disadvantage of this type of approach.
} 
According to this view, obligatorily controlled PRO and the first person pronoun both have their value supplied by the author coordinate of the context against which they are interpreted. This parallel captures the essentially first personal nature of de se thoughts: if John expected to become rich and famous he had the thought, "I will become rich and famous". That John does not have this thought in a situation where he fails to recognize himself explains why (117a) is judged false.

A context-shifting semantics for expect can be adapted to derive the possibility of PC given the assumption that contexts, qua world-time-individual triples, can be extensions of other contexts:

\section{8. $\llbracket$ expect $\rrbracket^{c, g}=\lambda \chi \lambda x \lambda t \lambda w . \forall c^{\prime}\left[c^{\prime} \in \operatorname{Dox}_{x, w, t} \rightarrow \exists c^{\prime \prime}\left[c^{\prime \prime}\right.\right.$ is an extension of $\left.\left.c^{\prime} \& \llbracket \chi \rrbracket^{c^{\prime}, g}=1\right]\right]$} Where $\operatorname{Dox}_{\mathrm{x}, \mathrm{w}, \mathrm{t}}=\left\{\mathrm{c}^{\prime}\right.$ : it is compatible with what $\mathrm{x}$ believes in $\mathrm{w}$ at $\mathrm{t}$ for $\mathrm{x}$ to be author $\left(\mathrm{c}^{\prime}\right)$ and w to be world( $\left(c^{\prime}\right)$ and t to be time $\left.\left(c^{\prime}\right)\right\}$

A problem with this analysis is that because it treats PRO as a semantically contentful item that is not abstracted over, there is no mechanism to ensure deletion of the feature [singular] that it inherits from the controller in a PC sentence. Partially controlled PRO would then be interpreted as an atomic entity and it would be mysterious how a collective predicate could combine with it. As the two systems stand, an account based on binding of PRO in the syntax - the property view - is more successful than a context-shifting view in accounting for the tension that we find between the plurallike and singular-like behaviors of the understood subject of a PC sentence. ${ }^{23}$

\section{$\underline{5.4 \text { Directions for future work }}$}

An important respect in which this work lags behind the syntactic literature on partial control is that we have not considered the cross-linguistic picture. ${ }^{24}$ In this subsection we will suggest directions for future work by identifying questions that our proposal raises for cross-linguistic research on infinitives, particularly in the domain of simultaneous predicates. In section 3.3 we argued that a stative simultaneous predicate such as exceptional case marking believe is expected to be unable to embed an eventive predicate; the ability of emotive factives to do so was taken as evidence that their semantics has a meaning component akin to that of the progressive. Yet there are many languages that have a control variant of believe that can embed an eventive predicate; (Boskovic, 1997) provides examples from French, Portuguese, Spanish and Italian. We illustrate this with an Italian example:

$\begin{array}{llllll}\text { 119. Anna credeva } & \text { di } & \text { arrivare } & \text { in ritardo } & \text { ieri } & \text { mentre } \\ \text { Anna believed } & \text { to } & \text { arrive } & \text { late } & \text { yesterday } & \text { though }\end{array}$

$\begin{array}{llll}\text { era } & \text { in realità } & \text { in } & \text { orario } \\ \text { she.was } & \text { actually } & \text { on } & \text { time }\end{array}$

[(Boskovic, 1997): 64, fn 21, ex (i)(c)]

Given our reasoning concerning emotive factives in section 3.3, this suggests that the semantics of (control) believe in these languages incorporates existential quantification over extensions, thereby permitting partial control.

\footnotetext{
${ }^{23}$ Unanswered questions still remain concerning the phi-features on PRO under the property view: as discussed in footnote 13, it remains to be spelled out how embedded C inherits the phi-features of the controller. We nonetheless think that the property view has the advantage, given that it offers a mechanism for deleting the phi-features of the controller on PRO, irrespective of how these features come to be inherited by PRO in the first place.

${ }^{24} \mathrm{I}$ am grateful to an anonymous reviewer for prompting me to think more about the issues discussed in this section.
} 
On the other hand, our analysis would in principle also be compatible with the existence of languages that have two routes to incorporating temporal notions in infinitives, one by appealing to extensions, and another involving covert tense or aspect markers. In this case, it need not follow that believe is necessarily predicted to license PC in these languages. A goal for future work should therefore be to establish whether there is empirical evidence for covert temporal operators in infinitives that cannot be handled by appeal to the semantics of the embedding predicate. Building on (Wurmbrand, 2007), a possible diagnostic would be to check whether in these languages infinitives with believe and other putative simultaneous predicates can behave like overt tense markers in acting as interveners for the purposes of licensing sequence of tense. Further empirical work is also needed to establish whether believe licenses partial control in Romance. Landau provides data suggesting that it does, but his examples involve auxiliary be, as in (120):

120. Il presidente crede di $\begin{aligned} & \text { esseri } \\ & \text { believe to be-SI }\end{aligned}$
the
la notte scorsa
the night last

'The chair believes to have gathered in vain last night.' [(Landau, 2000): 47, ex 58a]

As before, the crucial question is whether PC is licensed without the overt auxiliary; due to the delicacy of judgments concerning partial control we have been unable to elicit native speaker intuitions for these languages that point conclusively in one direction or the other. This is an area that would benefit considerably from experimental investigation.

\section{Conclusion}

We have shown that the property view of control infinitives is after all compatible with the existence of partial control. After motivating this view by showing that it correctly predicts the de se nature of obligatorily controlled PRO, we considered two possible semantics for PC that are both compatible with the notion that control complements express properties. According to the first, the individual argument of the embedded property is an individual that includes but need not be limited to the doxastic centre; this result is obtained by existential quantification over individuals that include the doxastic centre. According to the second candidate we considered, the existential quantification is not only over individuals that stand in a certain relation to the doxastic centre, but rather over extensions of centred worlds taken as a whole unit, where extensions are defined in terms of the relations between centred world coordinates belonging to the same type. A striking consequence of this second candidate is that it correctly predicts whether a given PC predicate belongs to the EC or PC class. Solutions to the other core puzzles concerning partial control also follow straightforwardly.

\section{Appendix}

Our template semantics for partial control predicates is weak in that it permits the subjective 'now' of the attitude holder t' to stand in any of a range of relations to the temporal coordinate t" of an extension: t' may be in the future with respect to t', in the past with respect to t', or it may include t'. We need a way to constrain this schema further in order to ensure that (i) future-oriented PC predicates do not tolerate past-oriented or progressive-like interpretations, (ii) past-oriented PC predicates do not tolerate future-oriented or progressive-like interpretations, and (iii) emotive 
factives do not tolerate future- or past-oriented interpretations. We can do this by defining three different classes of extension: future-oriented, past-oriented and progressive extensions.

\section{Future-oriented extension}

For any pair of world-time-individual triples $<\mathrm{w}, \mathrm{t}, \mathrm{x}\rangle$ and $\left.\left\langle\mathrm{w}^{\prime}, \mathrm{t}^{\prime}, \mathrm{y}\right\rangle,<\mathrm{w}^{\prime}, \mathrm{t}^{\prime}, \mathrm{y}\right\rangle$ is a future-oriented extension of $<\mathrm{w}, \mathrm{t}, \mathrm{x}>$ iff

(i) $<w^{\prime}, t^{\prime}, y>$ is an extension of $<w, t, x>$ and

(ii) $\mathrm{t}<_{\text {precedes }} \mathrm{t}^{\prime}$

\section{Past-oriented extension}

For any pair of world-time-individual triples $<\mathrm{w}, \mathrm{t}, \mathrm{x}>$ and $<\mathrm{w}^{\prime}, \mathrm{t}^{\prime}, \mathrm{y}>,<\mathrm{w}^{\prime}, \mathrm{t}^{\prime}, \mathrm{y}>$ is a past-oriented extension of $<w, t, x>$ iff (i) $<w^{\prime}, t^{\prime}, y>$ is an extension of $<w, t, x>$ and (ii) $t^{\prime}<{ }_{\text {precedes }} t$

\section{Progressive extension}

For any pair of world-time-individual triples $<\mathrm{w}, \mathrm{t}, \mathrm{x}>$ and $\left\langle\mathrm{w}^{\prime}, \mathrm{t}^{\prime}, \mathrm{y}\right\rangle,\left\langle\mathrm{w}^{\prime}, \mathrm{t}^{\prime}, \mathrm{y}\right\rangle$ is a progressive extension of $<\mathrm{w}, \mathrm{t}, \mathrm{x}>$ iff (i) $<\mathrm{w}^{\prime}, \mathrm{t}^{\prime}, \mathrm{y}>$ is an extension of $<\mathrm{w}, \mathrm{t}, \mathrm{x}>$ and (ii) $\mathrm{t} \subseteq \mathrm{t}^{\prime}$

The semantics of a future-oriented PC predicate incorporates existential quantification over futureoriented extensions; that of a past-oriented PC predicate incorporates existential quantification over past-oriented extensions; and that of an emotive factive incorporates existential quantification over progressive extensions. Recall also that we are assuming that attitude predicates are universal quantifiers over modal bases such as the following:

\section{4a. Doxastic alternatives (modal base for beliefs)}

$\operatorname{Dox}_{\mathrm{x}, \mathrm{w}, \mathrm{t}}=\left\{<\mathrm{w}^{\prime}, \mathrm{t}^{\prime}, \mathrm{y}\right\rangle$ : it is compatible with $\mathrm{x}$ 's beliefs in $\mathrm{w}$ at $\mathrm{t}$ for $\mathrm{x}$ to be $\mathrm{y}$ in $\mathrm{w}^{\prime}$ and for to be t'\} 4b. Say-alternatives (modal base for speech acts)

Say $_{\mathrm{x}, \mathrm{w}, \mathrm{t}}=\left\{\left\langle\mathrm{w}^{\prime}, \mathrm{t}^{\prime}, \mathrm{y}\right\rangle\right.$ : it is compatible with what $\mathrm{x}$ says in $\mathrm{w}$ at $\mathrm{t}$ for $\mathrm{x}$ to be $\mathrm{y}$ in $\mathrm{w}^{\prime}$ and for $\mathrm{t}$ to be $\left.\mathrm{t}^{\prime}\right\}$ 4c. Buletic alternatives (modal base for desires)

$\mathrm{Bul}_{\mathrm{x}, \mathrm{w}, \mathrm{t}}=\left\{\left\langle\mathrm{w}^{\prime}, \mathrm{t}, \mathrm{y}\right\rangle\right.$ : it is compatible with the fulfillment of $\mathrm{x}$ 's desires in $\mathrm{w}$ at $\mathrm{t}$ for $\mathrm{x}$ to be $\mathrm{y}$ in $\mathrm{w}$ and it is compatible with x's beliefs in $\mathrm{w}$ at $\mathrm{t}$ for $\mathrm{t}$ to be $\left.\mathrm{t}^{\prime}\right\}$

We can now provide complete sample lexical entries.

\section{Future-oriented PC predicates}

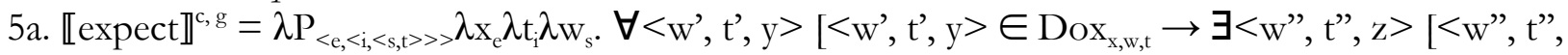
$z>$ is a future-oriented extension of $\left.\left\langle w^{\prime}, t^{\prime}, y>\& P(z)\left(t^{\prime \prime}\right)\left(w^{\prime \prime}\right)\right]\right]$

5b. 【intend $\rrbracket^{c, g}=\lambda \mathrm{P}_{<\mathrm{e},<\mathrm{i},<\mathrm{s}, \mathrm{t}\rangle>>} \lambda \mathrm{x}_{\mathrm{e}} \lambda \mathrm{t}_{\mathrm{i}} \lambda \mathrm{w}_{\mathrm{s}^{\prime}} . \forall<\mathrm{w}^{\prime}, \mathrm{t}^{\prime}, \mathrm{y}>\left[<\mathrm{w}^{\prime}, \mathrm{t}^{\prime}, \mathrm{y}>\in \operatorname{Dox}_{\mathrm{x}, \mathrm{w}, \mathrm{t}} \rightarrow \exists<\mathrm{w}^{\prime \prime}, \mathrm{t}^{\prime \prime}, \mathrm{z}>\left[<\mathrm{w}^{\prime \prime}, \mathrm{t}^{\prime \prime}\right.\right.$, $z>$ is a future-oriented extension of $\left\langle w^{\prime}, t, y\right\rangle$ \& in $w^{\prime \prime}$ at t', y brings it about that $\left.\left.P(z)\left(t^{\prime \prime}\right)\left(w^{\prime \prime}\right)\right]\right]$

5c. [promise $\rrbracket^{c, g}=\lambda \mathrm{P}_{<\mathrm{e},<\mathrm{i},<\mathrm{s}, \mathrm{t}>>>} \lambda \mathrm{x}_{\mathrm{e}} \lambda \mathrm{t}_{\mathrm{i}} \lambda \mathrm{w}_{\mathrm{s}} . \forall<\mathrm{w}^{\prime}, \mathrm{t}^{\prime}, \mathrm{y}>\left[<\mathrm{w}^{\prime}, \mathrm{t}^{\prime}, \mathrm{y}>\in \mathrm{Say}_{\mathrm{x}, \mathrm{w}, \mathrm{t}} \rightarrow \exists<\mathrm{w}, \mathrm{t}^{\prime \prime}, \mathrm{z}>[<\mathrm{w}\right.$, $\mathrm{t}^{\prime \prime}, \mathrm{z}>$ is a future-oriented extension of $\left.\left\langle\mathrm{w}^{\prime}, \mathrm{t}^{\prime}, \mathrm{y}>\& \mathrm{P}(\mathrm{z})\left(\mathrm{t}^{\prime \prime}\right)\left(\mathrm{w}^{\prime \prime}\right)\right]\right]$

These entries capture the intuitions that (a) if Mary expects to go to the movies, then she has the belief, "I will go to the movies", (b) if Mary intends to go to the movies, then she has the belief, "I will bring it about that I go to the movies", and (c) if Mary promises to go to the movies then she performs the speech act, "I will go to the movies". 
Past-oriented PC predicates

6a. 【remember ${ }_{\mathrm{PC}} \rrbracket^{\mathrm{c}, \mathrm{g}}(\mathrm{P})(\mathrm{x})(\mathrm{t})(\mathrm{w})$ is only defined if $\exists<\mathrm{w}^{\prime}, \mathrm{t}^{\prime}, \mathrm{y}>\left[<\mathrm{w}^{\prime}, \mathrm{t}^{\prime}, \mathrm{y}>\right.$ is a past-oriented extension of $\left.<w, t, x>\& P(y)\left(t^{\prime}\right)\left(w^{\prime}\right)\right]$

Where defined, $\llbracket$ remember $_{\mathrm{PC}} \rrbracket^{\mathrm{c}, \mathrm{g}}(\mathrm{P})(\mathrm{x})(\mathrm{t})(\mathrm{w})=\forall<\mathrm{w}^{\prime}, \mathrm{t}^{\prime}, \mathrm{y}>\left[<\mathrm{w}^{\prime}, \mathrm{t}^{\prime}, \mathrm{y}>\in \operatorname{Dox}_{\mathrm{x}, \mathrm{w}, \mathrm{t}} \rightarrow \exists<\mathrm{w}^{\prime}, \mathrm{t}^{\prime}, \mathrm{z}>\right.$ [ $<w^{\prime \prime}, t^{\prime \prime}, z>$ is a past-oriented extension of $\left.\left.<w^{\prime}, t^{\prime}, y>\& P(z)\left(t^{\prime \prime}\right)\left(w^{\prime \prime}\right)\right]\right]$

6b. 【regret $\rrbracket^{c, g}(P)(x)(t)(w)$ is only defined if $\forall<w^{\prime}, t^{\prime}, y>\left[<w^{\prime}, t^{\prime}, y>\in \operatorname{Dox}_{x, w, t}, \exists<w ”, t^{\prime \prime}, z>\left[<w^{\prime \prime}\right.\right.$, $t^{\prime \prime}, z>$ is a past-oriented extension of $\left.\left.<w^{\prime}, t^{\prime}, y>\& P(z)\left(t^{\prime \prime}\right)\left(w^{\prime \prime}\right)\right]\right]$

Where defined, $\llbracket$ regret $\rrbracket^{c, g}(P)(x)(t)(w)=\forall<w^{\prime}, t^{\prime}, y>\left[<w^{\prime}, t^{\prime}, y>\in B_{x, w, t} \rightarrow \neg \exists<w^{\prime \prime}, t^{\prime \prime}, z>\left[<w^{\prime \prime}\right.\right.$, $t^{\prime \prime}, z>$ is a past-oriented extension of $\left.\left\langle w^{\prime}, t^{\prime}, y>\& P(z)\left(t^{\prime \prime}\right)\left(w^{\prime \prime}\right)\right]\right]$

Where $\mathrm{Bul}_{\mathrm{x}, \mathrm{w}, \mathrm{t}}=\left\{\left\langle\mathrm{w}^{\prime}, \mathrm{t}^{\prime}, \mathrm{y}\right\rangle\right.$ : it is compatible with the fulfillment of $\mathrm{x}$ 's desires in $\mathrm{w}$ at $\mathrm{t}$ for $\mathrm{x}$ to be $\mathrm{y}$ in $\mathrm{w}$ ' and it is compatible with what $\mathrm{x}$ believes in $\mathrm{w}$ at $\mathrm{t}$ for $\mathrm{t}$ to be $\mathrm{t}$ '

Mary remembers going to the movies is only felicitous if Mary went to the movies at some point in the past. It reports that she believes that she went to the movies. Mary regrets going to the movies carries the same presupposition, and reports that for each of Mary's buletic alternatives $\left\langle w^{\prime}, t^{\prime}, y\right\rangle$, there is no time earlier than t' at which y went to the movies in w'.

\section{Emotive factives}

7a. $\left[\operatorname{glad} \rrbracket^{c, g}(P)(x)(t)(w)\right.$ is only defined if $\forall<w^{\prime}, t^{\prime}, y>\left[<w^{\prime}, t^{\prime}, y>\in \operatorname{Dox}_{x, w, t} \rightarrow \exists<w ”, t^{\prime \prime}, z>[<w ”\right.$, $t^{\prime \prime}, z>$ is a progressive extension of $\left.\left\langle w^{\prime}, t^{\prime}, y>\& P(z)\left(t^{\prime \prime}\right)\left(w^{\prime \prime}\right)\right]\right]$

Where defined, $\llbracket \operatorname{glad} \rrbracket^{c, g}(P)(x)(t)(w)=\forall<w^{\prime}, t^{\prime}, y>\left[<w^{\prime}, t^{\prime}, y>\in B_{x, w, t} \rightarrow \exists<w^{\prime \prime}, t^{\prime \prime}, z>\left[<w^{\prime \prime}, t^{\prime \prime}\right.\right.$, $\mathrm{z}>$ is a progressive extension of $\left.\left.<w^{\prime}, t^{\prime}, y>\& P(z)\left(t^{\prime \prime}\right)\left(w^{\prime \prime}\right)\right]\right]$

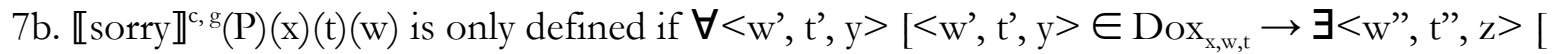
$<w^{\prime \prime}, t^{\prime \prime}, z>$ is a progressive extension of $\left.\left.<w^{\prime}, t^{\prime}, y>\& P(z)\left(t^{\prime \prime}\right)\left(w^{\prime \prime}\right)\right]\right]$

Where defined, 【sorry $\rrbracket^{c, g}(P)(x)(t)(w)=\forall<w^{\prime}, t^{\prime}, y>\left[<w^{\prime}, t^{\prime}, y>\in B_{x, w, t} \rightarrow \neg \exists<w^{\prime \prime}, t^{\prime \prime}, z>\left[<w^{\prime \prime}\right.\right.$, $t^{\prime \prime}, z>$ is a progressive extension of $\left.\left\langle w^{\prime}, t^{\prime}, y>\& P(z)\left(t^{\prime \prime}\right)\left(w^{\prime \prime}\right)\right]\right]$

Mary was glad to go the movies and Mary was sorry to go to the movies both presuppose that Mary believes that she went to the movies. The former asserts that for every $<w^{\prime}, t^{\prime}, y>$ such that it is desirable to Mary for her to be $y$ in w' and 't' is a candidate of hers for the actual time, there is a time that includes t' such that y goes to the movies in $w^{\prime}{ }^{26}$ The latter asserts that at every such $<w$ ', t', y> there is no time that includes t' such that y goes to the movies in w' at t'. We leave it as an exercise to the reader to construct parallel partial control examples.

Notice that the progressive-like meaning component of emotive factives is not identical to the semantics of the overt progressive morpheme. For one thing, the former appeals to an inclusion relation rather than a proper inclusion relation between time intervals. Moreover, in (Dowty, 1979)

\footnotetext{
25 This semantics is incomplete in that it does not account for the observation that when remember takes a gerundive complement, it is obligatorily interpreted as reporting a memory as experienced 'from the inside' in the sense of (Vendler, 1979). This requirement is responsible for the following contrast, based on (Higginbotham, 2000):

(i) I used to remember going to the movies when I was ten years old, but I no longer remember it.

(ii) \#I used to remember that I went to the movies when I was ten years old, but I no longer remember it. 26 Our rendering of buletic attitudes is much simplified; desires may well be better modeled via an ordering of centred worlds in terms of preferences. See (Heim, 1992, von Fintel, 1999) for relevant discussion.
} 
and subsequent literature the semantics of the progressive is augmented with an appeal to modal quantification to account for the possibility of an event marked with the progressive being unrealized in the actual world, as in John was writing a letter to Mary when a friend called and he forgot to finish it. Some data pointed out to us by an anonymous reviewer suggest that it is undesirable to incorporate this into the definition of progressive extension. In a situation where John didn't get round to finishing his letter it is false (or at least infelicitous) to say John was glad to write a letter to Mary; unlike with the overt progressive, the event in question must be realized in the actual world.

\section{Acknowledgments}

This paper develops ideas originally presented in Chapter 6 of my PhD dissertation (Pearson 2013). For helpful discussion I thank Gennaro Chierchia, Amy Rose Deal, Thomas Grano, Irene Heim, Norbert Hornstein, Manfred Krifka, Maria Polinsky, Jacopo Romoli, Uli Sauerland, Barbara Stiebels and audiences at the University of Maryland, NELS 43 and ZAS, Berlin. I am also grateful to three anonymous reviewers for extensive comments that significantly improved the manuscript. This research was partly supported by a Marie Curie FP7 Integration Grant within the 7th European Union Framework Programme, and by the Bundesministerium für Bildung und Forschung (BMBF) (Grant Nr. 01UG0711). 


\section{References}

Abusch, D. (1997). Sequence of tense and temporal de re. Linguistics and Philosophy, 20(1), 1-50.

Abusch, D. (2004). On the temporal composition of infinitives. In J. Gueron, \& Lecarme, (Eds.), The Syntax of Time (pp. 27-53). Cambridge, MA: MIT Press.

Anand, P. (2006). De De Se. Unpublished PhD dissertation, MIT.

Anand, P., \& Nevins, A. (2004). Shifty operators in changing contexts. Proceedings of Semantics and Linguistic Theory 14, pp. 20-37.

Bach, E. (1979). Control in Montague grammar. Linguistic Inquiry, 10, 515-531.

Barrie, M., \& Pittman, C. (2004). Partial control and the movement towards movement. Toronto Working Papers in Linguistics, 22, 75-92.

Bennett, M., \& Partee, B. (1972). Toward the Logic of Tense and Aspect in English. Bloomington, IN: Indiana University Linguistics Club.

Boeckx, C.; Hornstein, N., \& Nunes, J. (2010). Control as Movement. Cambridge: Cambridge University Press.

Boskovic, Z. (1996). Selection and the categorial status of infinitival complements. Natural Language and Linguistic Theory, 14, 269-304.

Boskovic, Z. (1997). The Syntax of Nonfinite Complementation: an Economy Approach. Cambridge, MA: MIT Press.

Bowers, J. (2008). On reducing control to movement. Syntax, 11, 125-143.

Chierchia, G. (1984). Topics in the syntax and semantics of infinitives and gerunds. PhD dissertation, UMass, Amherst.

Chierchia, G. (1989). Structured meanings, thematic roles and control. In G. Chierchia, \& B. Partee (Eds.), Properties, Types and Meanings II (pp. 131-166). Dordrecht: Kluwer.

Chierchia, G. (1990). Anaphora and attitudes de se. In R. Bartsch, J. van Benthem \& van Emde Boas, (Eds.), Semantics and Contextual Expression (pp. 1-32). Dordrecht: Foris.

Clark, R. L. (1990). Thematic Theory in Syntax and Interpretation. London; New York: Routledge.

Dowty, D. (1977). Toward a Semantic Analysis of Verb Aspect and the English 'Imperfective' Progressive. Linguistic and Philosophy 1(1), 45-77.

Dowty, D. (1979). Word Meaning and Montague Grammar: the Semantics of Verbs and Times in Generative Semantics and in Montague's PTQ. Dordrecht: Reidel.

Dowty, D. (1985). On recent analyses of the semantics of control. Linguistics and Philosophy, 8, 291331.

Enc, M. (1991). On the absence of the present tense morpheme in English. Unpublished manuscript.

Grano, T. (2011). Mental action and event structure in the semantics of try. Proceedings of Semantics and Linguistic Theory 21, Brunswick, NJ. pp. 426-443.

Grano, T. (2012). Control and Restructuring at the Syntax-Semantics Interface. Unpublished PhD dissertation, University of Chicago.

Heim, I. (1992). Presupposition projection and the semantics of attitude verbs. Journal of Semantics, 9, 183-221.

Heim, I. (2007). Person and number on bound and partially bound pronouns. Unpublished manuscript.

Higginbotham, J. (2003). Remembering, imagining, and the first person. In Barber, A. (Ed.), Epistemology of Language (pp. 496-533). Oxford: Oxford University Press

Hintikka, J. (1969). Semantics for propositional attitudes. In J. W. Davis, \& D. J. Hockney (Eds.), Philosophical Logic (pp. 21-45). Dordrecht: Reidel. 
Hornstein, N. (2003). On control. In Hendrick, R. (Ed.), Minimalist Syntax (pp. 6-81). Blackwell: Malden, MA

Jackendoff, R., \& Culicover, P. (2003). The semantic basis of control in English. Language, 79, 517 556.

Landau, I. (2000). Elements of Control: Structure and Meaning in Infinitival Constructions. Dordrecht; Boston, Mass.: Kluwer Academic Publishers.

Landau, I. (2003). Movement out of control. Linguistic Inquiry, 471-498.

Landau, I. (2004). The scale of finiteness and the calculus of control. Natural Language and Linguistic Theory, 22, 811-877.

Landau, I. (2006). Severing the distribution of PRO from case. Syntax, 9, 153-170.

Landau, I. (2008). Two routes of control: evidence from case transmission in Russian. Natural Language and Linguistic Theory, 26, 877-924.

Landau, I. (2010). The explicit syntax of implicit arguments. Linguistic Inquiry, 41, 357-388.

Landau, I. (2013a). Control in Generative Grammar: a Research Companion. Cambridge, UK: Cambridge University Press.

Landau, I. (2013b). A two-tiered theory of control. Unpublished manuscript.

Lebeaux, D. (1985). Locality and anaphoric binding. The Linguistic Review, 4, 343-363.

Lewis, D. (1979). Attitudes de dicto and de se. The Philosophical Review, 88(4), 513-543.

Maier, E. (2009). Presupposing acquaintance: a unified semantics for de dicto, de re and de se belief reports. Linguistics and Philosophy 32: 429-474.

Maier, E. (2011). On the roads to de se. Proceedings of Semantics and Linguistic Theory 21: 393-412.

Morgan, J. (1970). On the criterion of identity for noun phrase deletion. Papers from the Sixth Regional Meeting of the Chicago Linguistics Society, Chicago, IL. pp. 380-389.

Ogihara, T. (1996). Tense, Attitudes and Scope. Dordrecht: Kluwer Academic Publishers.

Ogihara, T. (2007). Tense and aspect in truth-conditional semantics. Lingua, 117, 392-418.

Percus, O., \& Sauerland, U. (2003). Pronoun movement in dream reports. NELS 33: Proceedings of the 33rd Annual Meeting of the North East Linguistic Society, MIT, Cambridge MA. pp. 347-366.

Pesetsky, D. (1992). Zero Syntax II: an Essay on Infinitives. Unpublished manuscript.

Petter, M. (1998). Getting PRO under Control. The Hague: Holland Academic Graphics.

Quine, W. V. (1956). Quantifiers and propositional attitudes. Journal of Philosophy, 53, 177 -

187.

Reinhart, T. (1990). Self-representation. Lecture delivered at Princeton conference on anaphora, October 1990. Ms.

Rodrigues, C. (2007). Agreement and flotation in partial and inverse partial control configurations. In Davies, W.D., \& S. Dubinsky (Eds.), New Horizons in the Analysis of Control and Raising (pp. 213-229). Dordrecht: Springer.

Sauerland, U. (2003). A new semantics for number. Proceedings of Semantics and Linguistic Theory 13, 258-275.

Schlenker, P. (1999). Propositional Attitudes and Indexicality: A Cross-Categorial Approach. Unpublished $\mathrm{PhD}$ dissertation, MIT.

Schlenker, P. (2003). A plea for monsters. Linguistics and Philosophy, 26, 29-120.

Sharvit, Y. (2003). Trying to be progressive: the extensionality of try. Journal of Semantics, 20(4), 403445.

Stephenson, T. (2007). Towards a Theory of Subjective Meaning. Unpublished PhD dissertation, MIT.

Stephenson, T. (2010a). Control in centred worlds. Journal of Semantics, 27, 409-436.

Stephenson, T. (2010b). Vivid attitudes: centred situations in the semantics of remember and imagine. Proceedings of Semantics and Linguistic Theory 20, 147-160. 
Taylor, B. (1977). Tense and continuity. Linguistics and Philosophy, 1, 199-220.

Uegaki, W. (2011). Controller shift in centred-world semantics. Handout of talk given at workshop on Grammar of Attitudes, $33^{\text {rd }}$ Meeting of the German Linguistic Society, University of Göttingen.

van Urk, C. (2010). On obligatory control: A movement and PRO approach. Unpublished manuscript. Vendler, Z. (1979). Vicarious experience. Revue de Métaphysique et de Morale, 84, 161-173.

Vlach, F. (1981). The semantics of the progressive. In P. J. Tedeschi, \& A. Zaenen (Eds.), Syntax and Semantics, vol. 14: Tense and Aspect (pp. 271-292). New York: Academic Press.

von Fintel, K. (1999). NPI licensing, Strawson entailment, and context dependency. Journal of Semantics, 16, 97-148.

von Stechow, A. (2002). Binding by verbs: Tense, person and mood under attitudes. Unpublished manuscript. von Stechow, A. (2003). Feature deletion under semantic binding. Proceedings of the North East Linguistics Society.

White, A.S., \& Grano, T. (2013). An experimental investigation of partial control. Poster presented at Sinn und Bedeutung 18, University of the Basque Country.

Wilkinson, R. (1971). Complement subject deletion and subset relations. Linguistic Inquiry, 2, 203-238. Williams, E. (1980). Predication. Linguistic Inquiry, 11, 203-238.

Witkos, J., \& Snarska, A. (2008). On partial control and parasitic PC effects. SKASE Journal of Theoretical Linguistics, 5, 42-75.

Wurmbrand, S. (1998). Infinitives. Unpublished PhD dissertation, MIT.

Wurmbrand, S. (2001). Infinitives: Restructuring and Clause Structure. Berlin/New York: Mouton de Gruyter.

Wurmbrand, S. (2002). Syntactic vs. semantic control. In C. J. Zwart, \& A. Werner (Eds.), Studies in comparative germanic syntax: Proceedings from the 15th workshop on comparative germanic syntax (pp. 95129). Amsterdam: John Benjamins.

Wurmbrand, S. (2007). Infinitives are tenseless. Penn Working Papers in Linguistics Vol 13.1: Proceedings of the $30^{\text {th }}$ Annual Penn Linguistics Colloquium. 407-420.

Wurmbrand, S. (2014). Tense and Aspect in English Infinitives. Linguistic Inquiry 45.3, 403-447. 